BNL-NUREG-50806

7

\title{
AN ANALYSIS OF SORS: A COMPUTER PROGRAM FOR ANALYZING FISSION PRODUCT RELEASE FROM HTGR CORES DURING TRANSIENT TEMPERATURE EXCURSIONS
}

\author{
J.M. Dickey
}

HTGR SAFETY DIVISION

Date Published - April 1978

DEPARTMENT OF NUCLEAR ENERGY BROOKHAVEN NATIONAL LABORATORY UPTON. NEW YORK 11973 


\title{
AN ANALYSIS OF SORS: A COMPUTER PROGRAM FOR ANALYZING FISSION PRODUCT RELEASE FROM HTGR CORES DURING TRANSIENT TEMPERATURE EXCURSIONS
}

\author{
J.M. Dickey
}

\author{
Manuscript Completed - December 1977 \\ Date Published - April 1978
}

\author{
HTGR SAFETY DIVISION \\ DEPARTMENT OF WUCLEAR ENERGY \\ BROOKHAVEN NATIONAL LABORATORY \\ ASSOCIATED UNIVERSITIES, INC. \\ UPION, NEW YORK 11973
}

PREPARED FOR THE UNITED STATES NUCLEAR REGULATORY COMMISSION DIVISION OF REACTOR SAFETY RESEARCH, OFFICE OF NUCLEAR REGULATORY RESEARCH UNDER CONTRACT NO. EY-76-C-02-0016 
TABLE OF CONTENTS

Section

Page

Abstract

$v i i$

Lis: of Tables

iv

List of Figures

$\mathrm{v}$

I. Introduction

1

II. Tine Core Design and the Mathematical Model Used in

4 SORS

1II. The Physical Data and Models Required for the

Calculation

IV. The Mathematical Equations and Compucational

Techniques Lsed in SORS

$\because$ Release From trie ive? Particies

VI. Diffusion Through the Graphite

VII. Evaporation and Deposition in thr Coolant Channels

VIII. Sumary of Observations

ix. Conclusions

References

Tables

Figures 
Table 3.1 Fission Product Classification by Chemical and Thermodynamic Similarities

Table 3.2 Diffusion Cuefficients for Elements in Graphite

Table 3.3 Freundich Isotherms of Certain Fission Products

Table 3.4 Vapor Pressures of Elenents in a Graphite System

Table 3.5 Monolayer Concentrations in Graphite

Table 6.1 Approximate Diffusion Times in Hours at the Stated

Table 0.2 Temperature $\left({ }^{O} E\right)$ Required for Approximate Diffusion Times of One Hour and One Day

Mole 7.1 Dimensionless Numbers in the Coolant Channei During 60 Release ó̃ $\mathrm{Sr}$ 


\section{LIST OF FIGURES}

Eigure 2.1 HTGR Euel particles. ${ }^{2}$

'age

Figure 2.2 Large HTGR fuel element design. ${ }^{2}$ o2

Figure 2.3 HTGR ccre and support arrangement. ${ }^{2} \quad 62$

Figure 2.4 Typical SORS model. 2

Figure 2.5 Barriers to the release of fission products. 64

Figure 3.1 Generalized decay chain structure. $\quad 64$

Figure 3.2 Evolution of the average and maximum temperature 65 of the core.

Figure 3.3 Evolution of the temperature of the 10 segments 65 in the central part ci the core.

Figure 4.1 Sumary of mathematical approach to release 66 from the fuel.

Figure 4.2 Comparison of the release from the fuel of ${ }^{131}$ I, 67 132 I, 133 I predicted by FKCALC and SORS.

Figure 4.3 Comparison of the release from the fuel of ${ }^{144} \mathrm{Ce}, \quad 67$ $140 \mathrm{Ba}$ predicted by FKCALC and SORS.

Figure 4.4 Fraction released from fuel for each segment in the centra? part of the core, predicted oy FKCALC.

Figure 4.5 Fractional release rate fror fuel For each segment in the central part of the core, predicted by FKCALC.

Figure 4.6 Release from the fuel for ${ }^{135}$ I, predicted by FKCALC and SORS.

Figure 5.1 The release from the fuel predicted by FkCALC using Fuel Model $I$.

Figure 5.2 The release from the fuel predicted by FKCALC using Fuel Model II.

Figure 5.3 Comparison of the two fucl models for ${ }^{85} \mathrm{Kr}$. 70

Figure 5.4 Comparison of the two fuel models for ${ }^{131} \mathrm{I}$. 70

Figure 5.5 Comparison of the two fuel models for ${ }^{137} \mathrm{Cs}$. 71 
Figure 5.6 Comparison of the two fuel models for ${ }^{35} \mathrm{Nb}$.

Figure 5.7 The effect of the model for fuel iailure using

Figure 5.8 The effect of the model for fuel failure using

Fuel Model I, $85 \mathrm{kr}$.

Figure 5.9 The effect of the model for fuel failure using

Fuel Model II.

Figure 5.10 Comparison of the release from the fuel for a

uniform core with the release for a core divided into 56 segmencs.

Figure 6.1 The two alternative approximations for diffusion used in SORSG.

Figure 6.2 The amount of ${ }^{90}$ Sr released from the fuel, curve 1 , and the amount that has diffused through the graphite, 76 culve 2 , on the assumption that eyaporation is instantaneous and no redeposition occurs.

Figure 7.1 Variation of temperature along the coolant channels in the central portion of the core. The full curve refers to 21 hours and the dashed curve to 29 hours.

Figure 7.2 Experimental data and theoretical curves for mass transfer in a fluid flowing through a cylindrical channel.

Figure 7.3 Comparison of the output of SORSG and the results predicted by the code if the expression for the evaporation rate is change to Eq. (7.27).

Figure 7.4 Comparison of the release of ${ }^{90} \mathrm{Sr}$ assuming that initially $0 \%, 10 \%$ or $100 \%$ of the $90 \mathrm{Sr}$ has been released from the fuel particles.

Figure 7.5 Comparison of the results using SORSG and EVAP.

The full curve is predicted by EVAP and the dashed curve is predicted by SORSG. 


\section{ABSTRACT}

The code SORS was written by General Atomic to calculate the release of fission products from the Euel into the primary coolant during a hypochetical uncontrolled transient temperature excursion. The code assumes that the graphite core remairs structurally intact. The release from the Euel particles is calculated using a coarse time step for sev-ral sections of the core. For the non-volatile elements, the code calculates a diffusion rate and an evaporation rate in each section of the core. The expression used for the evaporation rate is found to be incompatible with the rest of the assumptions used in the calculation. 


\section{Introduction}

An analysis of a maximum hynothetical fission arouct release is requind for the evaiuation o: a reactor sice. This release is estimated

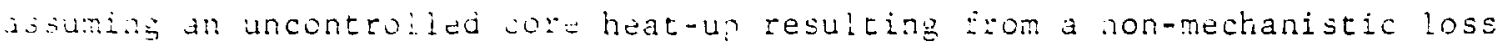
oi cooling. The fue! particle coatings and the graphite roderator sill delay the escape of the fission products from the core of a high temperature gas cooled reactor, HTGR, to the interior of the fre-stressed concrete reactor vessel, PCRV. The fission products may then leak out of the PCRV inco the containment. The code SORS $^{2}$ was written by Schwartz et. al. to. crat the first stage in the reiease of the fission products during a Eansient cemperature evcursion, nameiy from the core of the reactor to the oritary cooiant circuit.

Tha core of an HTGR consists oi several graphite biocks which contain the fuel. The core is cooled by helium gas which circuiates through coolant channels bored in the graphite. The core and the primary coolant system is encased in a PCRV. Under norma? operating conditions the helium is at a pressure of about 725 psia and is circuiated by 3 curbine driven axia: Elon compressois at a rate of $11 \times 10^{6}$ lb/hr. There are, in addition, tince aukilary cooling loops in case of failure of the main cooling system. In the hypothetical accident to be considered it is assumed that all the circulators have failed so there is no forced circulation of the He. Sucin a Eailure vould result in an immediate reactor trip. The subsequent decay of the fission products would generate a considerable amnunt of heat. In the absence of forced circulation this heat cannot be ranow suficiently quicaly by conduction and radiation, therefore the 
tamperature of the core is not maintained within the range of normal operacing conditions, but vill gradually rise to the sublimation cemperature of granite. Schwartztrauber and Silady ${ }^{3}$ have astimaced that after about 10 hours, the maximum temperature anywhere in the core will be about $4800^{\circ} \vec{F}$, and afrer about 50 hours, about one third of the core will be at $6500^{\circ} \mathrm{F}$. Before the accident occurs, almost all the fission products present will be contained within the fuel particles. Some fission products may be plated out on surfaces of the primary coolant circuit. These amounts are expected to be small, in a reactor which has a normal operating history, so the effect of 1 i.:t off will not be discussed here. As the temperature DE the core increases we can describe oualitatively what may be expected to occur. There will be no immediate release of the fission products, as che particle coatings are almost impervious until the temperature has risen several hundred degrees ajove operating temperatures. However, in the course of time, juring the assumed accident, as the temperature reaches higher values, the fission products can diffuse through the coatings and the coatings themselves are eventually degraded. The expected performance of the coatings as a function of temoerature and oast fluence must be hased or experimental data and is necessary input for the calculation. The rurl particles are packed in a graphite binder and stacked in holes drilled in graphit o blocis. One may conservatively assume that the most volatile elements, the rare gases and the halogens, are released directly into the primary coolant circuit after escaping from the fuel particles. So for these elements it is onl: necessary to calculate the release from the fuel pait cles: this is done in the varsion of the code, SORSD. The release of the nom-volatile elements on the other hand is retarded by the 
graphite moderator. These elements nust diffuse across the graphite web to the coolant channel surface and evaporate directly irom this surface. Initially this process will merely resule in a redistribution of tae Eission products as the nobile elements will evaporate from the hotter regions o: the core and redeposit in the cooler regions. As the cooler parts of che core heat up and the reflectur also heats up, eventually some of the atoms can escape from the core into the upper plenum. The version SORSG of the basic code SORS calculates these stages of the release of the non-volatile fission products. In the analysis used in SORS of a loss of coolant accident, it is assumed that the integrity of the graphite core is maintained, that carbon is lost from the core only through sublimation and that the amount lost is negligible.

The code SORS is described in detail in a licensing topical report, GA-LTR-10. 2 The output of the code has been quoted in several Safety Analysis Reports, e.g. Fort St Vrain FSAR, ${ }^{4}$ Fulton PSAR ${ }^{5}$ and GASSAR, ${ }^{6}$ and also in the Accident Initiation and Propagation Analysis (AIPA) report. 7 The results from SORS also have been used as a source term. For the dispersal from the containment in other studies. ${ }^{8}$ one version of SORS vas received from General Atomic on March 10, 1975. This version calculated only the release from the fuel and incorporated the fuel nodel described in GA-LTR1C. 2 Two other versions of the code, SORSD and SORSG, were received from General Atomic on February 10, 1976. The later version used a different fuel model, which is similar to that described in the AIPA report. ${ }^{7}$ This report is based on an analysis of these versions of the codes and the published documentacion.? 
The vojcotive of this vork is to examine the adequacy or ine code sors as a means of calculating the consequences oi the postuiated accident sce-

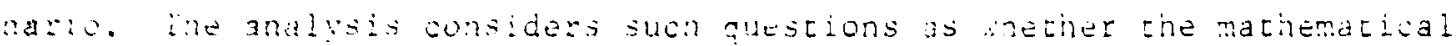
moie: is adequate or whether the computational cechnique is appropriate; the report discusses the relative importance of difierent factors, insofar as they bear on the choice of the mathematical approximations used in the code. It was not the purpnse of this study to exercise the code. Chapter 2 describes the core of an HTGR. Chapter 3 describes the data and models o: the physical processes used in the code. Chapter 4 describes the mathmatical structure of the code. Chapters 5-7 describe the stages in the migratin or a ísion product. Chapter 8 summarizes the observations. II. Core design and the mathematical model used in SORS

The Euel is contained in spherical fuel particles which have a ceramic coating (Fig. 2.1). The rissile fuel is uranium enriched with $235^{U}$ in the Form of $\mathrm{UC}_{2}$. The parcicles of $\mathrm{UC}_{2}$ are $200 \mathrm{~mm}$ in diameter and have a triso coating consisting of a low density pyrocarion buffer layer followed by a bigh density pyrocarbon layer, a SiC layer and an outer high density pyrocarbon layer. The Eertile fuel particles contain kernels of Tho whose diameter is $500 \mathrm{~cm}$. These particles have a biso coating consisting of an inner buffer layer of low density nyrocarbon and an outer layer of high density pyrocarbon. At nomal operating temperatures the fuel particle coatings are almost impermeable to the fission products. The rate at which Eission products can leak out of the particles increases as the temperature is raisec. At a sufficiently high temperature, the coatings fail and the issifor products can escape readily. The fuel particle behavior is 
discussed Further in Chaptur 5 .

The ruel particles are mixed with carbonized bitch and graphise flour and the mixture is formed into cylindrical fuel rods. The fuel rods have a diameter of .618 in and are 31.22 in long. The fuel elements are hexagonal blocis of graphite through which are drilled an array of holes (Fis. 2.2). Some of these holes contain a fuel rod or burnable $?$ : ison and the remaining holes are the coolant channels along which the helium flows. Each standard fuel element contains 132 fuel rods and 72 crolant channels. The fuel rods are sealed in the fuel holes by a graphite plug. Eight fuel elements are stacked in a vertical column and similar blocks of graphit ar. placed at the top and bottom to act as reflectors. The coolant channels of adjacent elements are aligned by dowel pins. The columns are arranged in rerueling regions each of which contains 7 columns except at the outer edge of the core. The active core, in a proposed design for a 3000 MWt reactor, contains 4 ( 2 fuel columns and is surrounded by a permanent side reflector consisting of graphite (Fig. 2.3). The core is supported on graphite blocks and held in place by a lateral zestraint structure. One quarter of the fuel is replaced each year. The fluence experienced by a girnn fuel particle depends on its location in the core as well as the age of the fuel and operating history of the reactor. Consequently the inventory of fission procucts will vary from one particle to another. The cors is modelled mathemati -dliy in a simple cylindrical geometry (Fig. 2.4). The core is divided into up to 14 concentric radial regions and 10 axial segments, one corresponding to each fuel element, and two fo: the ton reflector. The properties of each radial region are calculated by averaging 
Wer the fuel eluments in the cor:espunding annular portion oi the reactor core. Thus inatial variations within the core are partially taten into kount. For example, for each jegment the fraction of the fuel ahich is $\therefore 2,3$ o: 4 years old is calculated from the arrangement of the reiuelins regions and this informazion is used as data by the code.

The objective of SORS is to calculate the time taken for the fission products to migrate from the furl particles to the upper plenum. The migration of the atoms is modelled as a succession of barriers; this is sho.mn Eiguratively in Fig. 2.3. The first stage of the calculation concerns the relcase from a Euel particle. This is discussed in detail in Chater 5 . It i: assmied "hat the ísion product atoms can move freely through the loose graphite binder surrounding the fuel particles. The volatile fission products are hardly retarded by the qraphite matrix, but escape directly from tine fuel particles into the primary soolant. Two further stages in the calculation are required for the non-volatile fission products, the c:ffusion through the graphite matrix and evaporation at the coolant channel suriace; thase stages are discussed in Chapters 6 and 7. II. Phvsical data and models required for the calculation

In this chapter we discuss the data that must be supplied for the calculation. Some of this data is Eixed for a particuiar planc, e.g. geometrical data concerning the dimensions of the core of a 3000 MWt plant. Dther data are based on the results of experimental tests or are taken from the output of another code. Insofar as there is some uscertainty in the latter data it is necessary to determine the sensitivity of the release rates predicted by SORS to variations in the data. Some physical properties 
are not wnown directly and so general considerations must be used to generate the required data. Following is a list of the da a used by SoRs to;:ther with the rejerencas on the sources.

1) Geometriza! data conceriang the redctor.

a) Physical data determined by the plant under consideration, e.g. diameter of coolant channels, size of graphite blocks.

b) Data determined by the mathematical model of the core, e.g. number and size of the regions into which the core is divided.

2) Mathematical data for the computation.

For example, initial time step, number of significant Eigures, maximum error in the integration.

3) Historical data, which depend on the prior operating history os the reactor.

a) Inventory of fission products in the core at the start of the incident. The inventory will depend on the time elapsed since the last refueling and also on the power level during the past 4 years. The amounts of short lived Eission products will attain an equilibrium value, but the amounts of longer lived fission products will increase approximately linearly with time. The amourt of rission products will be at $a$ maximum. just prior to refueling. The inventory used as input in SoRS has been calculated using the code RAD. ${ }^{9}$ This code takes account of the different fission yields of ${ }^{235} \mathrm{U}$ and ${ }^{233} \mathrm{U}$. RAD also partially calculates the effects of the parents and grandparents of an isotope, but it does not calculate the results of neutron capture. 
) Distribution of fission products in the core.

$\mathrm{RAD}$ astimates the total inventory of fission products through-

out the cole. The rission products are not unitormly dispersed

but the concentration will vary from one part of the core to

another. This variation is expressed by supplying a power

factor for each axial node and a power iactor for each radial

node. The fraction of the inventory in a given portion of the

core is theu given by $P_{A} P_{K} V$, where $P_{A}$ and $P_{R}$ are the relevant

axial and radial power factors and $V$ is the volume of the

portion $0:$ the core. The product $\mathrm{P}_{\mathrm{A}} \mathrm{P}_{\mathrm{R}}$ varies from .54 to 1.28

in the samole data. The power distributiuns in the different

refuting regions are calculated using core physics codes 10

and the power factor for each radial region is calculated by

averaging over the included refueling regions.

c) The relative amounts of biso and triso fuel particles for each radial region.

4) Decay schemes and data for the decay chains.

The code allows for decay chains with a maximum of 6 members and For a simple branching pattern (Fig。3.1).

5) r.mperature history or the core.

The temperature history of each region of the core is calculated by the parallel code CORCON. ${ }^{3}$ The two aspects of the problem, the migration of the fission products and temperature evolution of the core, have been decoupled in soRs. The consistency of this assumption cou'd he checied by using the results of SORS in 
a econd teration of CoRCon: a discussion ji such an iteration i. outside the scope or this review, which is restricted to a consideration or SoRS. The temperature of the core rises slorly. Fir. 3.: shows the average and maximum ternerature of the core versus cime; arier 10 hours the average temperature is abou= $3000^{\circ} \mathrm{F}$ and after 20 hours $4200^{\circ} \mathrm{F}$. The temperature evolution varies in different parts of the core. Fig. 3.3 shows the temperature sequence for the segments in the cen'ral region or the core.

6) Coolant fiow raze and pressure.

Following a pipe rupture the helium escapes into the containment. The change in pressure is calculated in the code corTEyPTG. 11 If the containment remains intact the oressures in the PCRV and the containment reach equilibrium with a value of 39.8 psia after about $10 n$ seconds. The pressure then falls to 29.0 Doia at 20 minutes and 27.8 psia at 24 hours. In this accivent it is assumed that there is no forced circulation so that the flow of helium is due to natural convection caused by the tot core. Because of the large resistance to flow, the Elow rate will be very slow and has been estimated by H. W. Che and G. J. Malek, using the code RECA, 1 ? to range from $.034 \mathrm{lb} / \mathrm{hr}$ at about . I hr to $5 . \mathrm{c} \times 10^{-5} \mathrm{lb} / \mathrm{hr}$ at about 50 hours. The corresponding Reynolds numbers are 6.9 and 0.0041 so the flow is laminar and far below the transition to turbulent flow, which occurs at Reynoids numbers of about 200 .

7) Fuel release characteristics. As the temperature rises the capacity of the fuel particles to 
تatain the iission nroducts lecreases. The probability of fission Product: escaping from the flel particles at different emperatures is needed for the code. Experimerital daia is riatlable based on beth in pile and out of pile tests. The esperimental results have a vide spread and several models have been suggested based on the results. ${ }^{2,1}$ The data and these adels have betn reviewed extensively in two topical reports. ${ }^{14,15}$ so it is unnecessary to discuss the valudity of the basic data; this report is concerned with the extent to which the variations in the data and the different empirical models affect the calculations in SORS, namely the release curves for dirferent isotopes. This topic is discussed in dutail in Chapte: 5 . The data for some elements are similar so the elements are grouped into 10 classes shown in Table 3.1 , and carameters for each class are specified.

8) Difiusion ccefficients in graphite and partition coefficient between the graphite binder and graphite blocks. Norman ${ }^{16}$ has revieved the available data. Experimantal values for the diffusion coeficients are available only for $\mathrm{Sb}$ and a few ocher elements. 16 For the remaining elements Norman suggests the data in Table 3.2, which are based on a heurisic relationship between the activation energy for diffusion and the vapourization energy. This expression involves a considerable extrapolation From known experimental results. Another variable which affects the diffusion of an impurity is the partition of the impurity between the two types of graphite in the core, the loose binder 
yraphite and the graphite blocis. Unce dgain there is only slight experimental data jo there could be deviations Exom the value of 15 suggested by Noman. 16

?) Vapour pressure.

Experimental vapour pressurc data are available for many elements and their carbides. The data have been collected and revieved by Norman. 16 For $\mathrm{Cs}, \mathrm{Rb}, \mathrm{Ba}$ and $\mathrm{Sr}$ Freundich isotherms are used above a cricical concentration $\mathrm{C}_{0}$, and Langmuir isotherms are used for lower concentrations:

$$
\begin{array}{lll}
\text { for } & C \cdot C_{0} & \ln P=A+\frac{B}{T}+\left(A^{\prime}+\frac{B^{\prime}}{T}\right) \ln C \\
\text { and for } & C C_{0} & \ln P=A+\frac{B}{T}+\left(A^{\prime}-\frac{B^{\prime}}{T}\right) \ln C_{0}+\ln \frac{C}{C_{0}}
\end{array}
$$

where $P$ is the pressure

$I$ is the temperature

$C$ is the concentration

$A, B, A^{\prime}, B^{\prime}$ are the vapour pressure constants, Table ?.3. For $C_{s}$ a value of $C_{0}=0.078 m$ molesim ${ }^{2}$ has heen observed; the same value is adopted for the other 3 elements. For the remaining elements an Arrhenium equation is used. Since the chemical form, in which the element is present, is not known, the vapour pressures of the free element and the carbide are added together in SORS. This assumption overestimates the vapour pressure and so will overestimate the evaporation rate but will underestimate the deposition rate. If the surface coverage is less than a monolayer, the dersity of the vapour in equilibrium with the surface will be 
les. than che saturatod vapour density oi the same temperature. It is assumed that the satura.ion yabour dersity is scaled by the sam Eaction as the suriace coverage. Another prameter is thui introduced, namely the concutration oi impurity corresponding to the monolayer coverage. This has been estimated by Norman 16 from geometrical considerations, based on the close packing of spheres with the appropriate atomic radii. So the expression used for the vapour pressure is:

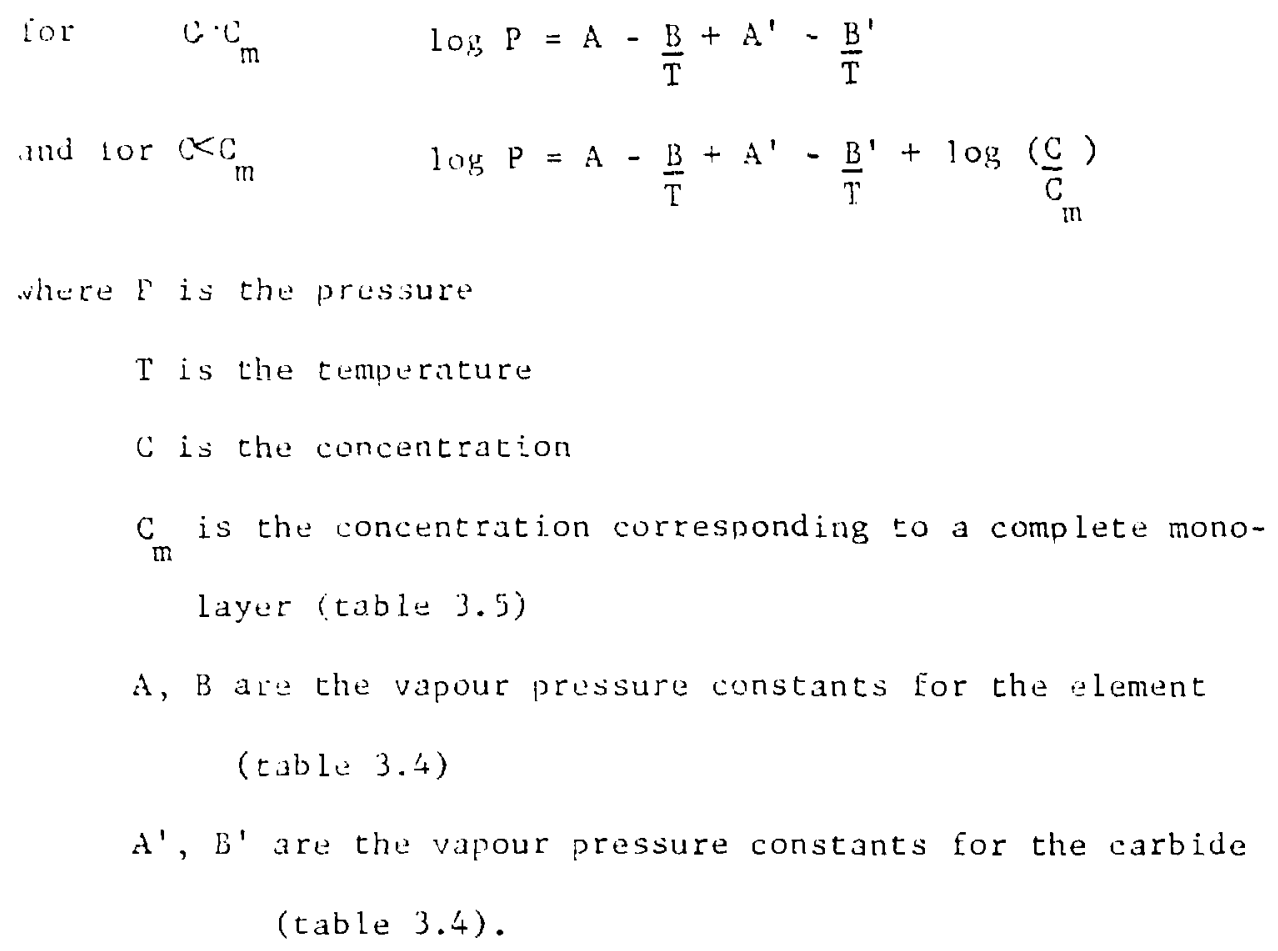

IV. Mathematical equations and computational techniques used in sors

The procedure adopted in SoRs is to describe the problem in terms of ieveral coupled first order differential equations with coefficients which are denendent on time. The independent variables represent the total arount si ach isotone in one oi the three parts of the core - the fuel, 
the graphite or the primary coulant. The variable evelicicints represtet a average pobability ot an atom moving from one fat of the core to ambh-

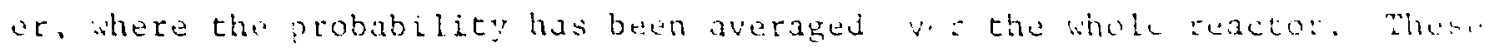

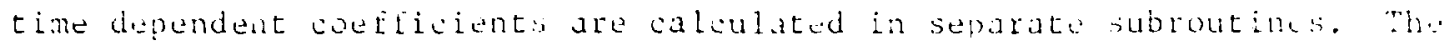
dirterntial equations are integrated numerically using itamings rredictor - corrector technique. Since Hamings technique is a Eour step method, a Runge-Kutta routine is used to set up the stating wilues. Hammings method is well established and has several advantages. A comparison of the predicted and corrected values permits an estimate w the arror in the inteatation and also enables the time stop to be autonatically adjusted durina: the course of the calculation. So the integrating anowdure is accurate? and ruliable. In general, a computacion requires a rumerical method which is as accurate as the equations which are to be integrated.

We will use the following notation, which is different from that used in $\operatorname{LTR}-10$. $^{2}$

$$
\begin{aligned}
& \mathrm{N}_{\mathrm{i}}=\text { total number of atoms of isotope } \mathrm{i} \text { in the reactor } \\
& \mathrm{n}_{i}=\text { total number of atoms of isotope } i \text { in the tuel particles } \\
& m_{i}=\text { total number of atoms of isotrpe } i \text { in the graphite moderator } \\
& r_{i}=\text { total number }: i \text { atoms of isotope } i \text { in the primary coolant circuit. }
\end{aligned}
$$$$
\text { It is assumed that the atoms of the volatile elements can pasis directly }
$$
into the coolant after escal ing from the fuel, so for the volatile elements:

$$
N_{i}(t)=n_{i}(t)+r_{i}(t) \quad 4.1
$$

The non-volatile elements are delayed in the graphite, so for the nonvolatile lements:
$N_{i}(t)=n_{i}$
$(t)+m_{i}$
(t) $+r_{i}$
4.2 
The change in the number of atoms of an isotope "i" due to radioactive decay depends on the decay ronstant ${ }_{i}$ and the probability of $P_{i j}$ of a precuin "j" iecaying into "i". So the difjerential eouation for the total number of acoms of any isotope is:

$$
\frac{d}{d t} N_{i}=-\lambda_{i} N_{i}+\sum_{j} P_{i j} N_{j}
$$

where the summation is ove: all precusors.

In Fig. 2.1 we show schematically the disposition of an isotope between the fuel, graphite and coolant. We can define fractional release rates, $F, G$, which at a given time represent the probability of an atom moving from one of these three media to another. For example if the number or atoms of a given isotope in the fuel at time $t$ is $n(t)$ then the rate at which thuse atoms escape from the fuel at this time is $-F(t) n(t)$. Similarly if $m(t)$ is the number of atoms of an isotope in the graphite the rate at wich these atoms move from the graphite into the primary coolant circuit can be written as $-G(t) m(t)$.

In tems of these release rates the coupled differential equations for the number of atoms in different parts of the core are as follows: For the amount in the fuel particles $n_{i}$,

$$
\frac{d}{d t} n_{i}=\left(-\lambda_{i} n_{i}+\sum P_{i j} n_{j}\right)-F_{i} n_{i} \quad 4.4
$$

where the first bracket on the right hand side represents the effects of radioactive decay, as in $E_{q} .4 .3$, and the second term is the rate at which atoms are released from all the fuel particles. The remaining equations differ for the volatile and non-volatile elements. For volatile elements, it is assumed there is no retention in the graphite so the equation for 
the amount released inco the primary coolant, $r_{i}$, is

$$
\frac{d}{d t} r_{i}=\left(-\dot{r}_{i} r_{i}-I P_{i j} r_{j}\right)+E_{i} n_{i}
$$

The term in brackets is due to decay and the last term is the relea f:om the fuel. For the non-volatile elements, the corresponding equation Evr the amount i= the primary coolant, invoives instead the release rate from the graphite, $G_{?}{ }_{i}$,

$$
\frac{d}{d t} r_{i}=\left(-\lambda_{i} r_{i}+\Sigma P_{i j} r_{j}\right)+G_{i} m_{i}
$$

The amount in the graphite, $m_{i}$ is calculated from tha equation for conservation of mass

$$
m_{i}=i_{i}-n_{i}-r_{i} \quad 4.7
$$

Having set up the mathematical formulation of the problem in this :orm, if the functions $F(t)$ and $G(t)$ were known, the problem would be reduced to a simple numerical integration. The combination of Hammings method and the Runge-Kutta method would be an appropriate technique. However che release rates, $F$ and $G$, have been defined in a purely formal manner. The value of these release rates represents an average over the whole reactor and depends not only on time explicitly but also on the distribution of the fission products throughut the reactor.

Stage I Release from the fuel particles, subroutine FKCALC

First we shall discuss the release from the fuel particles. Let us coisider one individual fuel particle " $\alpha$ " and denote by $\nu_{i}^{\alpha}$ the amount of the isotope " $i$ " in this fuel particle. For this fuel particle at a specified ime there is a well defined iractional relaase rate $f_{i}^{\alpha}$ which depends on the temperature of the particle and which can be calculated irom the 
input data. The differential equation for $y_{i}^{x}$ is:

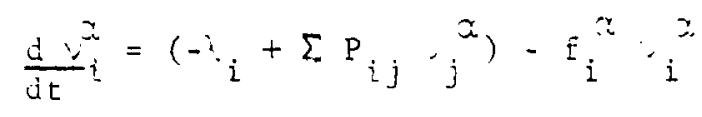

The total amunt of the isotope in all iuel particles is

$$
n_{i}=\sum_{2} v_{i}
$$

differentiating this equation and substituting from e.g. 4.8

$$
\begin{array}{lll}
\frac{d n}{d t} n_{i} & =\sum \frac{d}{d t} v_{i}^{\alpha}=\sum_{a}\left(-\lambda_{i} \nu_{i}^{\alpha}+\sum_{j} P_{i j} \nu_{j}^{\alpha}\right)-\sum_{a} f_{i}^{\alpha} v_{i}^{\alpha} & 4.10 \\
\frac{d n}{d t} n_{i} & =\left(-\lambda_{i} n_{i}+\sum_{j} P_{i j} n_{j}\right)-\sum_{\alpha} \dot{f}_{i} \nu_{i}^{\alpha} &
\end{array}
$$

This is the exact equation governing the release from fuel particles. Comparing the two Eqs. 4.4 and 4.11 , the formal release rate for the whole core is:

$$
\begin{aligned}
& E_{i} n_{i}=\sum_{z} \vec{E}_{i}{ }_{i}^{\alpha}
\end{aligned}
$$

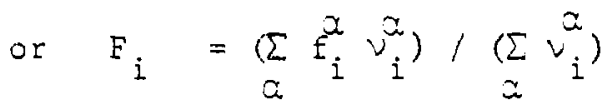

To find $F_{i}$ exactly it is necessary to know the contents of each fuel particle, that is to have the solutions of the differential equations, Eq. 4.11, For all the fuel particles. So far nothing has been achieved by the introduction of the formal release rate $F$. The procedure adopted in SORS is to decouple the calculation of $F$ from the solution of the equation involving decay.

F is calculated approximacely in subroutine FKCALC. Eq. 4.8 is replaced by a simpler equation in which decay is neglected:

$$
\frac{d}{d t} \vec{v}_{i}=-\tilde{t}_{i} \vec{v}_{i}
$$


Since the decay data has been elimirated, the same equation holds for all isotopes of a given element. For simplicity we shall ignore, in the nathematical discussion, the differences between biso and triso particles and the intact and iailed state. Let us consider one particular segment oi the core and one element. The input data includes a table of the temperature of the segment versus time. Using the fuel failure model the release rate for the chosen element is calculated at each of the temperatures in the table. Eq. 4.14 is integrated using a simple stepwise method. Take the release rate to be constant between the times in the table then if $x$ is the value of the release rate during a time interval to the amount in the iuel particles alls by a fraction $e^{-x \delta t}$ in this time interval. Thus the amount of the element within the fuel particles contained in the segment, and also the ralease rate from the fuel particles for that segment, are calculated versus time in FKCALC. This procedure is repeated for all the segments into which the core is divided and all the classes of elements. The overall release rate from the fuel particles for the whole reactor is now calculated from Eq. 4.13. The output of FKCALC is a table of average fuel particle release rates versus time For each of the 10 classes of the elements. The main program uses this tible of release rates, interpolating where necessary, to find the time dependent coefficients in the original differential Eq. 4.4. This equation is then integrated using Hamings method. This lengthy discussion is summarized in Fig. 4.1.

Since FKCALC calculates quickly an approximate release curve from the fuel elements, it is of interest to compare this curve with the results 


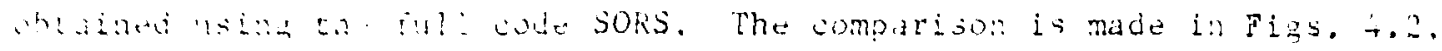

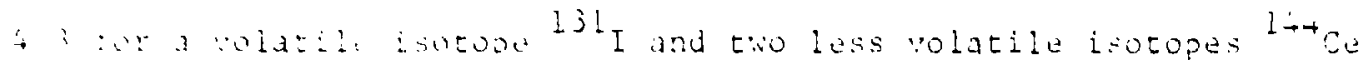

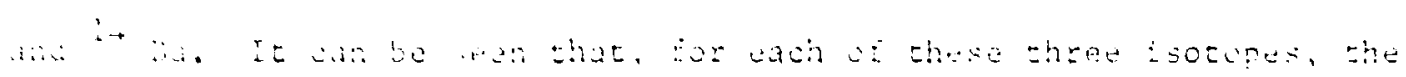

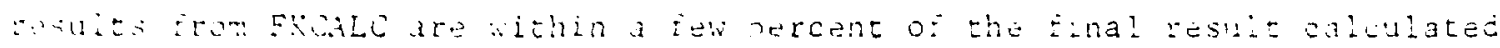

$\therefore$ soRs, wesite the aiganence in accuracy oi the incegration algorithms

Whet in the tio sases. Yoreover the time step used in FKCALC is very

arge, 1.5 hours between 4.5 and 10.5 hours, compared with the time step

Hed in lamings routine. Which time step is initially set at $10^{-4}$ hours.

The aditional computer time has affected the results very little, in these examales.

I: : :he exict Es. 4.8, the amount of an isotope in a fuel particles An shando iuc to radiogctive decay or because atoms migrate out of

the Euel particle. If one of these terms is much larger than the other then the simpler difEerential equation involving only the larger term is an adequate approximation. This vill be so in the folloving circumstances:

a) Short lived isotope with no precursors, i.e. i>f. Such isotopes are not of interest in this problem since they will have decayed to a fraction of their initial activity before it is possible for them to be released.

i) Long lived isotope. Since most of the release occurs in the time span $5-15$ hcurs, the activity of isotopes with a half life greater than this time will not change much during release, so the decay cerm can be neglected. Fig. 4.3 shows release surves for ${ }^{13}$ I, which has a half life of 8.05 days and ${ }^{13}$ I which has a half life of 2". 3 hours. FKCALC gives a very good approximation for ${ }^{131}$ I 


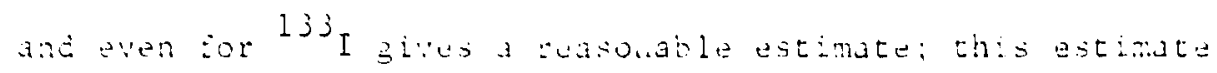
coula be improved simaly by scaling by $e^{-i t}$.

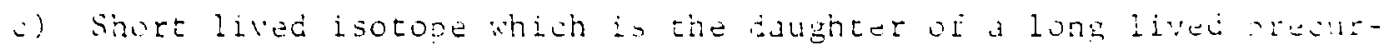

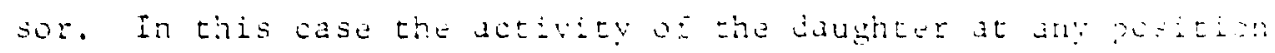
is deternined by the activity and migration rate or the parent. An example is the parent-daughter pair ${ }^{132} \mathrm{Te}$, half life 78 hour. and ${ }^{132}$ I, halé life 2.28 hours. Since $T e$ and $I$ are both in ciass 10 their migration rates are the same. Although the activity of the ${ }^{132}$ I atoms originally present in the core would have decreased by a Eactor of about 1.: in 2 il hours, Eis. 4.2 shovs that during this time, FKCALC provides a joul approximation to the total activity or ${ }^{132}$ I calculated using sors.

The release curve and the release rate will vary in different regions of the core. Fig. 4.4 shows the release curves from FKCALC for Xf for the 8 segments into wich the central part of the core is divided (for the corresponding cemperature sequence see Fig. 3.3), and Fig. 4.5 shows the Eractional release rates for the same segments. Typically the release Erom the Euel particles occurs over a period $c=3-4$ hours betreen 4 and 10 hours after the accident, although in the cooler parts of the core these

* In the codes SORS, SORSD supplied by GA, and also in published data, e.g. GASSA ${ }^{6}$, account is not taken of the decay of an isotope after its releasu from the fuel. For example, GASSAR ${ }^{6}$ table $2 A$. 5-1, the amount of ${ }^{135}$ I, half 1 ife 6.7 hours is constant betweer. 32 and 48 hours. The correction would require a trivial change in the code. 


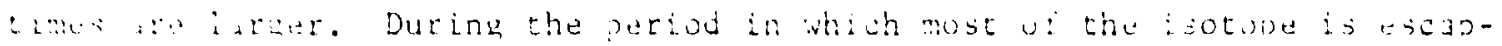

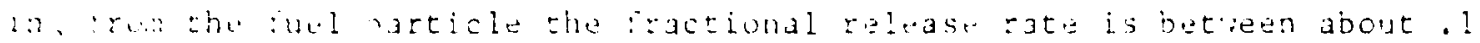

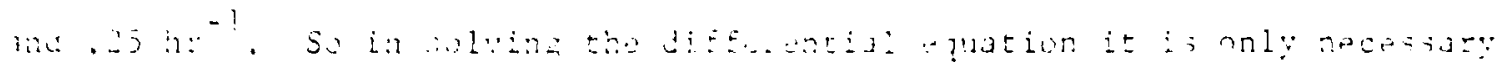

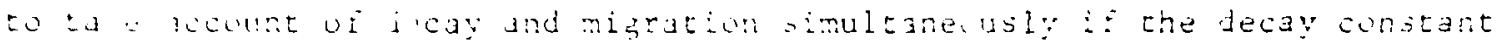
is nar the range . 2 to . $25 \mathrm{hr}^{-1}$, or if the precursors ot an isotope are such that $\approx{ }_{j} P_{i j} \ddots_{j}{ }_{i}$ is in this range. An example $i^{3}{ }^{135} \mathrm{I}$, inich has a hali life oi 0.7 hours, and is shown in Fig. 4.6. Out of the 234 nuclides treated in SORS only abol:t 12 have values of $i$ in this range, so almost all ruclides all inco the 3 categories for which either decay or migration is dominant. For those isotopes wich do nor fall in these catezories, the procedure dionted in Sons, of dropoing one or the two nearly equal tarms in Eq. 4.8, introducas a large aporoximation. This approximation is not compensated Eor by using an accurate numerical integration later in the calculation. For nost isotopes the results of the full code and FKCALC are equally accirate.

Stage 2 Di Efusion of the non-volatile elements through tha graphite and their transport by the coolant, subroutine RELEAS

Aiter they h. : escaped irom the fuel particles, the non-volatile Sission products are still confined by the graphite matrix. The scenario assumes that the graphite matrix remains intact. In order to reach the upper flenum of the primary coolant circuit, the fission products must diffuse through the graphite to the coolant channel, evaporate at the surface of the channel and be carried out of the channel by the coolant stream. The mathematical approach in SORSG to the second stage of migration is similar to the approach taken in the release from the fuel particles so .e ill not repeat the details. The differential equation, 


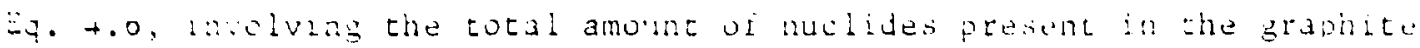

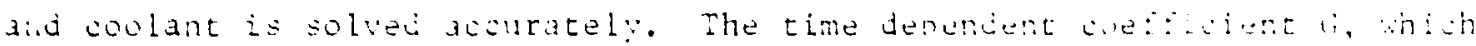
woresses the average orobability or an aton escaning l.wn the srant te

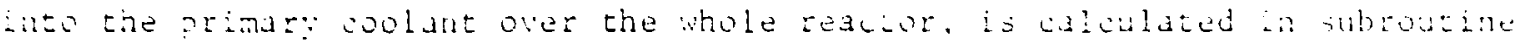
RELEAS.

In subroutine RELEAs the core is divided into 14 l segments. For each segment, a difierential equation for the amount of the element in the coolant channel is solved. The equation is similar to Eq. 4.14 used in Fkcilc; decay is neglected and the Fractional release rate represents the probability of migration from the graphite to the coolant, or vice versa. A maximal zate of release controlled by difiusion is crlculated on the assumption that evaforation is instantaneous. A release rate cuntrolled by evaporation is also calculated on the assumption that diffusion is instantaneous. The lesser of these two release rates is taken as the net release rate in the code. It is assumed that the lower value indicates the rate determining process. The differential equation is solved using a crude stepwise method and a time interval of .5 hour. The remarks made in the previous section on FKCALC about the mathematical technique for decoupling the effects of decay and transport apply equally to RELEAS. There are, in addition, several other considerations:

1) Since some transport phenomena depend in a non-linear manner on the concentration, e.g. Freundlich isotherms, it is necessary to treat all the isotopes of an element at the same time. This is done in RELEAS.

2) RELEAS calculates the transport of the isotopes of the element 
under consideration. The rulabe uf progenitors irom the fued is twien into account but the transport of proysnitos through the

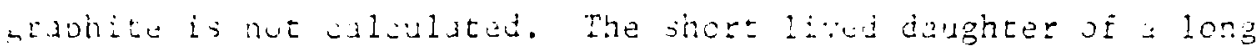
lived parant is everyines in quasi equilibrium with the parent so the transport it the jaughter í determined by the nigration of the parent. Any isotope falling into this category is not calculated correctly by the code.

3) The calculation required in EKCALC was simpler in that the release Erom the Euel particles in one section of the core did not depend directly on the release in any other section of the core. In the presut case the coolan strum carries the atoms along the coolant channels and atons which have evaporated from one section of the core may redeposit back in another part of the core. RELEAS takes this flow along the coolant channels into account.

4) Eor any isotope, the total amount, which has been released from the Euel particles in the whole core, is used as a source tem for the second stage of the release. In other words the two stages of release, out of the isel and into the coolant, have been decoupled in SORSG. Consider one particular section of the coze. The amount of an isotope available to migrate through the graphite depends on the local release rate from the fuel particles, that is on the local temperature. Thus use of an average source term for the second transport stage, instead of the true source term, will be an overestimete in those regions of the core where the remperature is lover than average, and will be an underestimate in those 
ragicns whose temperature is higher than average. Since miar:aiu: ates are higher in the hotter sections, this approximation tends to underestinate tho amount released at any one time, and so tini asumption is aor conservative. Whether the consequences at tis assumption are important depends on whether the migration rates are high at the temperature at wiscir release occurs fron the fuel. If the migration rate oi an isotope is low at these temperatures then transport will not become appreciable wntil a later time when the temperatures nave risen, and so the exact time dependence of the source term is not important.

In the freatrent of the iirst stage o: release, combining hit averaging performed in FKCALC with numerical integration in the main program, did not appear to change the results appreciably. In the second stage of release because the transport process is more complex it is possible that alternately calculating an average in RELEAS and then integrating the average in the main program may introduce inaccuracies.

V. Release Erom the fuel particles

The Eirst stage in the release of the fission products is their escape irom the fuel particles. The volatile elements, $\mathrm{Xe}, \mathrm{Kr}, \mathrm{I}, \mathrm{Br}, \mathrm{Se}$ and $\mathrm{Te}$ are assumed to escape directly into the primary coolant but for the remaining elements the amount released from the fuel is the source term for the second stage in the release. Briefly, a fuel model provides the probability of fuel failure versus temperature, and also release rate functions versus temperature for both intact and failed particles. The data may depend on the age of the particle and the fluence and temperature history. The tio 
yersions of sons supplied by Ga incurporated two dizi=rent iuel mudels; one similar to that ised in LTRlo' and the ocher imilus to that used in AIPA. 7 The models are liscussed in detail in reterences i- and is. These

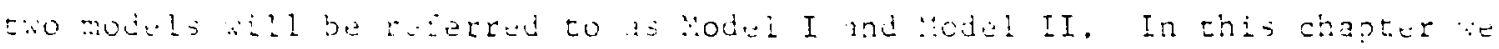
SEscuss the influence of sevral factors on the relejse irom the fuel particles.

1) Psults zor ditierent chemical plements

Th ? elements are divided into 10 classes such that the experimental data for the members of any one class is similar. The first two Eigures, 5.1, 5.2. show the release curves for the 10 classes as calculated in FkCALC for the t:o fuel models. This is a convenient ay oi compessing the results, since it was shown Chapter 4 that Eor nost nuclices, which have moderate or long litetines, the release curves, which have been calculated using the whole code, are approximately the same as the results of FKCALC. The curves from FKCALC are not smooth because of the large time step, 1.5 hours, used; $50 \%$ of the release occurs over a time span of about 5 hours, ard the curves approach $100 \%$ sluvly, as some portions of the core remin lelatively cool for a long time.

2) Effect oi Euel madel used

The next four figures, $5.3-5.6$, show the difference between the two fuel models. The results are the output of the full code. Two volatile elements ${ }^{85} \mathrm{Kr}$ and ${ }^{131} \mathrm{I}$, one moderately volatile element ${ }^{137} \mathrm{Cs}$ and one refractory element ${ }^{95} \mathrm{Nb}$ are shown. For ${ }^{131} \mathrm{I}$, Fig. 5.3, a member of class 10 , there is a significant difference in the consequences of the two models. The time, at which $50 \%$ is released. 


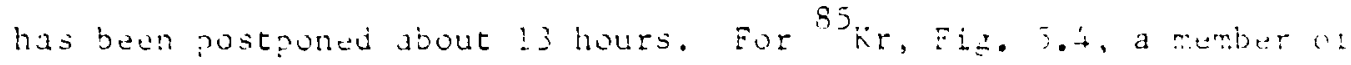
Llass 0 , there is also a signiticant ditzerence, the release curve

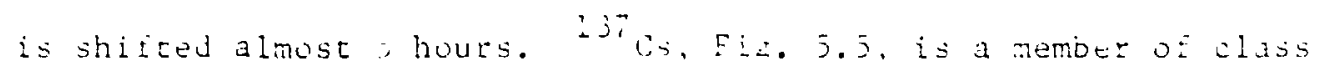
․ This is the oniy class ior wich the second ibel model predicas release irom the ruel at an earlier zime than the iirst model. The curves are displaced by about 1.2 hour. For ${ }^{95}$ xib, Fig. 5.6, which is a member of class 7 , the release from the fuel occurs about 3i4 hour later using Yodel 2. Eigs. $5.1-5.6$ show that difierences between the models postulated to fit the empirical fuel particle data for one element results in differances between the relaase curves Eor chat element comparable to tine differences between the curves for different elements.

\section{3) Efiect of Euel failure characteristics}

The rate at which fission products can escape from fuel particles which have intact coatings is very much less than from fuel particles whose coatings have a small hole or are cracked. A small Eraction of the fuel particles have impaired coatings even as manufactured. During the normal operation of the reactor ic is expected that the coatings of a few more particles will deteriorate. As the reactor heats up the pressure inside the particles will increase and more coatings will fail. The fuel particle cod ans fail at lower temperatures in the first fuel model than in the second fuel model so the effects of the ruel failure characteristics are different in the two cases.

For Nodel I the fuel fails at temperatures at which the 
reledsu rate iunction frum a salled particle is low. So an apprecLable amount of a íssion product does not escape until some time atcer luel tailure, when the temperature of the particle has risen. Thus the details of the temperature range, within wich iuel failure vcaurs, are not importait. To taie an extreme example suppose all of the particle coatings have failed prior to the accident. On this hypothesis only the release rate data for failed particles is used in the calculation. Figs. 3.7 and 5.8 show the release curves assuming $100 \%$ failed fuel, compared with the usual failure moisl, for ${ }^{131} \mathrm{I}$ and $85 \mathrm{kr}$. The dirierence is only detectable at whort times less than about 5 hours; For ${ }^{131}$ I there is a difference oi $17 \%$ at 2 hours, $3 \%$ at 3.5 hours, $1 \%$ at 5 hours; for ${ }^{35} \mathrm{Kr}$ the difierence is $21 \%$ at 2 hours, $4 \%$ at 3.5 hours and $1 \%$ at 5 hours. In Euel Yodel II, by contrast, the fuel particle coatings Eail at a higher temperature, so the fission products thereupon can escape rapidly. Fig. 5.9 shows the fraction of triso and biso particles, which have failed, versus time. Superimposed are the relaje curves for three isotopes. For the classes of elements 1. the release curves are close to the ruel failure curve, showing that the model for fuel failure versus temperature is the controlling factor in determining the time of release. For ${ }^{13} 1_{I}$ and the other elements in class 10 the escape rate function is important, as in the first fuel model.

\section{4) EfEect of temperature sequence}

The remperature history of tine core is provided by the code 
Corcon. ${ }^{3}$ For cumbleteness, the impact of uncertaincies of the temperature sequence on zhe SORS results was imestigated. In Eig. 4.t the release curves are shown for ke for 8 segments of the core in the central region. The temperacure nistories of these segments are shown in Fig. 3.3. The release curve for a given segment depends sersitively on its cemperature hiscory. There is a big difference between the release curves for different segments. So a change in the temperature histories of the individual begments could affect the average release curve for the whole core.

5) Eifect of the number of segments in the mathematical model ol the core

In the first version of the sode which we received, the core was divided into 56 segments, and in the second version ther were 112 segments. The simplest assumption would be to consider just 1 segment, in other words to assume that the whole core is at a uniform temperature and at any time this temperature is equal to the average temperature calculated by CORCON. ${ }^{3}$ Fig. 5.10 shows the release curves for the uniform core model compared with the results based on 56 segments. The very crude calculation gives a good estimate of the time taken for about $50 \%$ of a fission product to be released. From the point of view of the accident under consideration this is the essence of the calculation. The curves for the uniform core differ in the tails at long and short times. This is to be expected, for at short times some parts of the core are at a higher temperature than the average temperature and so 
the ralease fiom thuse parts of the core will be yreacer than from the uniform core. At long times sume parts oi the core dili be much cooler than the average and wili seili reain the rission sroducts. So the release curie for the core with a distributed remperature will be above the release curve for a unizorm core at short times, and below for long times.

VI. Difiusion through the graphite

The evaporation rate at the surface of a coolant channel is a boundary conjition for the partial differential equation describing the difiusion through the graphite. Thi, is a complex problem, so in SOkSG, diffusion mi a $\because$ aporation are treated indepentently. The code essentially makes one OE two extreme assumptions. In each small section of the core either the process is controlled solely by the rate of diffusion or solely by the rate of evaporation. In the first case it is assumed that any atoms reaching the coolant channel surface evaporate instantaneously and moreover, that the concentratinn profile in the graphite, and the current, have the steady stat. values. The actual geometry of the core is complicated so in SORSG che graphite matrix is modelled as a cylinder surrounding the fuel hole, thus tha concentration profile is assumed to be logarithmic. The rate of release of an element into the coolant chinnel s taken to be equal to the stead: state diffusion current. In the second case it is assumed that evaporation is the controling process, and that diffusion is sufficiently rapid that the concentration profile is always uniform. In other words as atoms evaporate from, or are deposited on the surface, inigration to, or ::om, the interior occurs immediately to maintain an even concentration. 
The race of evaporation is calculated from the vapur pressure of the element in question. In SORSG, for each section of the cors, two potentiai reiease rates are calculated based on aach oi these two assumptions, Fis. 6.1. The sinaller of these two rates is assumed to indicare which is tht controlling process and this rate is then used as the net release rate.

In practice diffusion through the matrix web requires a certain amount of time, and also after the failure of the fuel it will require some time to establish either of the steady state concentration distributions assumed in SORSG. For example, initially, even if evaporation is instantaneous at the coolant channel surface, the diffusion current will be less than the steady state value and so use of the steady state current could lead to an underestimate of the time for the release of a small fraction of the fission product inventory. Noreover, especially ior the more refractory elements, the diffusiun rate is so slow that assumption of a uniform concentration may drasticaliy overestimate the possible evaporation rate, since the time required to establish a uniform concentration could be years. So, some calculations were made to determine rough guide lines as to the time scale required by the diffusive process alone. These times give a lower limit on the time required for release of the fission products because $O$ the additional time delay caused by evaporation, and also the possibility of deposition back on other cooler parts of the core.

Three simple cases, for which solutions are available, ${ }^{18}$ vere considered. The geometry and data, which were given in SORSG, were used. In the first two calculations it is assumed that the evaporation rate is very high so that the concentration at the surface of a coolant channel is 
$\therefore a: \ldots=0$. For a very small release, $1-2 \%$, the amount of the isotope in the iuel rod can change by a small fraction, so to estimate the time requiras we use the solution in which the concentration in the fuel rod is constant (Franci: ${ }^{18}$ ?. 84). To estimate the time required for a larger quantity to be released we use the transiant solution for the release from a cylinder within which the initial distribution is specified (Franck 18 p. 73). In Tables 6.1 and 6.2 are shown the results calculated for the release of a few percent and of about one third. Table 6.1 shows the estimated times at two temperatures; $2270^{\circ} \mathrm{K}$, at this temperature almost al1 iuel particles have failed so the fission products are available to diffuse through the graptite; and $3640^{\circ} \mathrm{K}$, which is the sublimation temperature of graphite, and so is the highest temperature attained by the core. From this table we see that at a constant temperature of $2270^{\circ} \mathrm{K}$ it would require more than 1.6 hours for a few percent of Pd to diffuse from the fuel hole to the coolant channel and longer for the elements more refractory than Pd. Even at the sublimation temperature of graphite more than 30 hours would be required for the diffusion of a few percent of the Mo and alements more refractory than Mo. So the most refractory elements will be retained in the core for long periods of time provided the graphite remains intact. Table 6.2 shows the results in terms of the temperature required for diffusion to occur in the specified time of 1 hour or 1 day.

The alternative assumption regarding diffusion in SORSG is that the concentration in the graphite web is always uniform. Because diffusion is not instantaneous, some time will elapse before the fission products have spread out uniformly from the fuel holes. Since in this model the 
diffusion rates are assumed to be very :apid, compared to the evapolacion rates, e will use the solution for the difiusion of an initial distribution within a evlinder, wich has an impermeable surrace (Francis ${ }^{18}$. 81 ). The results are shown in Tables 0.1 ani 0.2 . From Table 6.1 at 2.2. $\mathrm{K}$, see that for $\mathrm{Sb}$, about $1 / 2$ hour is required to establish an approximituly even concentration; and about 2.5 hours, at this temperature, would be required for an appreciable release, assuming no constraint were imposed on the rate of evaporation. So for elements more volatile than Sb, it is reasonable to calculate a vapour pressure based on the assumption of a uniform distribution of the element throughout the graphite. On the otider hand, elements aeter Pd require upwards of about 16 hours at $2270^{\circ} \mathrm{K}$ for the concentration to become uniform, so this assumption would overestimate the vapour pressure. After about 48 hours about half the core is at the graphite sublimation temperature of $3640^{\circ} \mathrm{K}$. For a section of the core at this temperature an even concentration distribution could be attained quickly, in less than 1 hour, for elements more mobile than Nd, whereas for Elements more reiractory than $U$ more than a day would be required. To consider the most refractory elements, $\mathrm{Nb}$ and $\mathrm{Zr}$, more than a year would be required to reach a uniform concentration, so obviously use of this assumption is unrealistic.

The migration of fission products from the fuel to the primary coolant involves an interplay of the two processes, diffusion and evaporation. The evaporation rate will depend on the rate at which the coolant flows through the coolant channels as well as on the temperature distribution. In SORSG we can eliminate the evaporation process and calculate a release curve in 
ahson the do! 3 minimum estimate oi the tines requirad for release ince the steady state

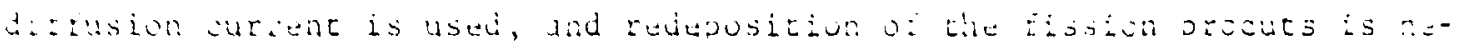

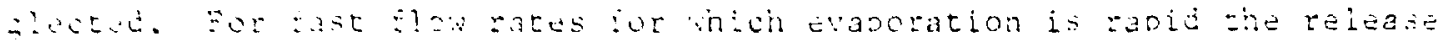
curves inll be close to this estimate. IE the Ilow rate is slow, the release curve will be displaced to larger times. Fig. 6.2 compares the curvas showing the release from the fuel and the release irom the graphite, assuming instantaneous evaporation and no redeposition, for ${ }^{90} \mathrm{Sr}$. It can be seen that the release curves are displaced by about 5 hours. So for ${ }^{21}$ Sr, difiusion alone implies an additional delay of about 5 hours in the Elinase Erom the core.

YI. Evaporacion and Deposition in the coolant channels

Aiter the fission product atoms have diffused through the graphite matrix to the coolant channel surface they may escape from the surface and be carried along the coolint chanizel by the flowing helium. Further along the coolant channel atoms may deposit back on the surface and then diffuse into the graphite. This cycle may be repeated several times before an atom emerges cut of the coolant channel into the upper plenum. At any place the nec loss by evaporation will depend on the local temperature and surface concentration of the graphite, the flow rate $n \bar{f}$ the coolant and the partial oressure of the element in the coolant.

The coolant channel is modelled by dividing it into a number of segments and the temperature is taken to be uniform within each segment. The change in temperature along the length of a coolant channel in the central portion of the core is shown in Fig. 7.1 for two difierent times. Fig. 
3. Showa the evoluti n in time of che temperature oi entral parts of the co:e. It can be seen in $5 i z$. 7.1 that sharp discontinuities in the temperature are sntroduced at th: boundary between tao segments. hovever the atements are chosen to coincide with the iuel elements so the thermal condustion Erom one element to another will be poorer than within one el ment. Direct difiusion from one fuel element to another is neglected.

As the coolant flows up the coolant channels, the fission products will evaporate from the graphite wall if the partial pressure in the coolant is less than the vapour pressure at the surtace of the channel. Conversely the Fission products will deposit back on the zraphite if the partial pressure is less than the vapour pressure. As the core heats up naterial vill initially evaporate from the hotter central segments and be redeposited on the cooler segments at the top and on the reflector. Eventually these segments heat up and the material re-evaporates. In order to calculate the evaporation rate, the assumption is made in SORSG that the distribution of the impurity is uniform throughout each segment of the core. If all the impurity present in a given segment has originated within the fuel particles contained in that segment, this is a conservative assumption, since the concentration at the coolant surface must be less than in the interior; however as discussed in Chapter 6 , this assumption may not be realistic at a temperature at which the diffusion rate is low. If we consider a portion of the top reflector, initially there are essentially no fission products present. However as the core heats up fission products will evaporate from the hot central portions of the core, will be carried up the cooiant channel and will redeposit back on the top reflector. To calculate the zate of 


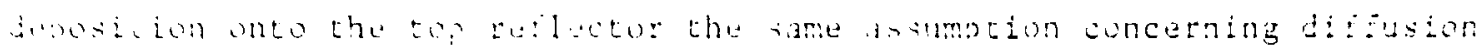

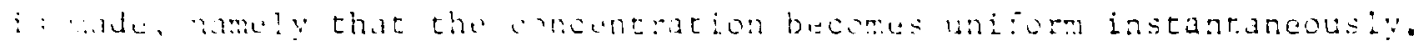

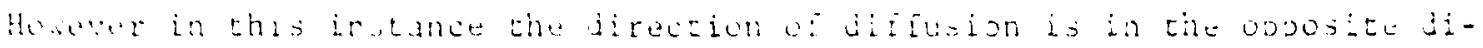

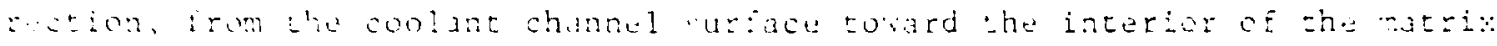
granita. Voreover the reflector is at a lower temperature than the rest or the core so diffusion rates are slower. The concentration at the surface will actuallv be higher than that calculated using a uniform concentration and there may be a buildup of impurity at the suriace, especially ior wemunts und temperatures for which the diffusion tate is low. Thus, the cifect of the assumption of infinitelv fast diffusion is, in this case, to overatinuta the rate of danosizion, and to underestimate the probability o: En impurity atom being carried out of the coolant channel. So the assumption is not conservative overall.

Development of an expression for mass transfer as described in LTR10 ${ }^{2}$ We quote the tollowing paragraph from LTR-10 ${ }^{2}$, section 5.4 page $5-16$. A coefficient $H$ is defined in Eq. 7.2.

"The vapor pressure at the graphite surface in a coolant channel, relative to the gas-phase partial pressure in the coolant channel, is then used in calculating the local mass transier coefficient. The release rate from the graphite into the gas phase of the coolant channel, or rate of condensation from the coolant and re-adsorption in the graphite, is then a function of the magnitude of the mass transfer coefficient and the direction of the pressure gradient from the bulk stream to the surface of the graphite: 


$$
\begin{aligned}
& \therefore(t)=H \because \frac{P_{b}-P_{0}, \quad(\text { LTR }-20-5.1)}{P_{j}} \\
& \text { where } R(t) \text { = evaporation or condensation } r \text { te (g sec), } \\
& \text { H = local mass transier coezicient calculated as a } \\
& \text { function of turbulent, lamiaar, or sublaminar } \\
& \text { Elow regime deined by the local Reynolds and } \\
& \text { Schmidt numbers, } \\
& \mathrm{W} \text { = carrier gas flow rate (g/sec), } \\
& P_{S}=\text { total system pressure (atm), } \\
& \underline{P}_{b} \quad=\text { temperature- and concentration-dependent element } \\
& \text { vapor pressure at the graphice surface (atm), } \\
& P_{C}=\text { element partial pressure in the coolant stream } \\
& \text { at the entrance to the core segment (atm)." }
\end{aligned}
$$

$R(t)$ is the total evaporation rate in (gisec) so the coeficient H, defined above, is a global mass transfer coefficient for the segment of the coolant channel under consideration. The term 'local' usually denotes a transfer coejficient rejerred to an ininitesimal segment. The use of $R(t)$ in the code is consistent with the assumption that both $R(t)$ and $H$ in Eq. 7.2 refer to global rates for a whole segment.

We quote the expressions given in section 5.5 .3 of LTR-10 ${ }^{2}$ for three different flow regimes:

\section{"5.5.3 Mass Transfer Film Coefficient}

The well-known Sherwood-Pigford relationship, based on

the heat mass transfer analogy, is used for the calculation 
ot the mass tansiar coeizicient. The mass transed coefficient

(H) Fot the enusing species through che coolant boundary layer

is based on both laminar and turbulent sloir considerations:

$$
\begin{aligned}
& \text { For Reynolds number - } 2100 \text { (tubulent flow), } \\
& \mathrm{H}=0.023 ;\left(\mathrm{Sc}^{0.67} \mathrm{Re}^{0.2}\right) ; \quad 7.3 \\
& \text { For Reynolds number }<2100 \text { and } L_{i}(d \operatorname{Re} S c)<0.07 \text {, } \\
& H=1.36(D / L \operatorname{Re~SC})^{1 / 3} /(\operatorname{Re} S C) ; \quad 7.4 \\
& \text { for Reynolds number }<2100 \text { and } L /(d \operatorname{Re} S c)>0.07 \text {, } \\
& \begin{array}{ll}
H=3.66 /(\operatorname{Re} S c) . " & 7.5
\end{array}
\end{aligned}
$$

$A$ correction Eactor, Eq. 5.20 of LTR-10" diffusion of the impurity through the boundary layer. Since this is approximately one for low impurity concentrations we will omit it, for simplicity, in our discussion.

Combining Eq. 7.2 with each of the possible expressions for $\mathrm{H}$, ve set

1) For $\operatorname{Re}>2100$

$$
\begin{aligned}
& R(t)=-0.023 /\left(R^{0.2} S c^{U .67}\right)-\left(W\left(P_{b}-P_{c}\right) / P_{s}\right) \quad 7.6 \\
& \text { 1: } \text { For } \operatorname{Re}<2100 \text { and } L /(\mathrm{dReSc})<.07 \\
& R(t)=\left[\begin{array}{lll}
1.86(\mathrm{~d} / \mathrm{L} & \operatorname{ReS} c)^{1 / 3} /(\operatorname{ReS} c)_{-}\left(W_{(}\left(P_{\mathrm{b}}-\mathrm{P}_{c}\right) / \mathrm{P}_{\mathrm{s}}\right) & 7.7
\end{array}\right. \\
& \text { 3) For } \operatorname{Re}<2100 \text { and } L /(\mathrm{deSc})>.07 \\
& R(t)=-3.66 /(\operatorname{ReSc})\rfloor\left(W\left(P_{b}-P_{c}\right) / P_{s}\right)
\end{aligned}
$$

Inspection of the code indicates that the expressions used to calculate :(t) are consistent with Eqs. $7.6,7.7$, and 7.8 . 
Let us apply these equations to tivo specilic examples.

Example 1 Fast ilow through a short jeyment, ibe assume that atie : ar. is surbulent so Eq. 7.6 is appropriate. If le substitute for the aconda: and Schmite numbers, we obain for the waporation rate

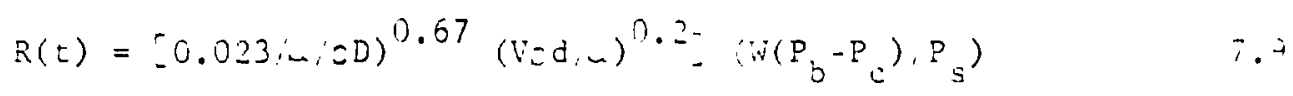

where $V$ is the velocity of the fluid in cm, s

$=$ is the density of the fluid in ${\mathrm{gm} / \mathrm{cm}^{3}}^{3}$

is the viscosity of the fluid in $\mathrm{gm} / \mathrm{cm} \mathrm{sec}$

$d$ is the diameter of the channel in $\mathrm{cm}$

$D$ is the diffusion coefficient of the impurity in $\mathrm{cm}^{2}$ sec and the other symbols are defined in Eq. 7.2. This equation does not include explicitly the length of the segment. So Eq. 7.9 predicts that the same number of grams would evaporate per second from a segment tivice as long as the original segment. For the flow conditions under consideration, we would expect, on physical grounds, that the concentration of the impurity in the vapour will change very slowly along the length of a tube. So the mass evaporated from a given segment should be approximately proportional to the length of that segment.

Example 2 Slow flow through a long segment. We assume that the Elo: is laminar and that the length of the segment is such that ( $L / D \operatorname{Re} S c$ ) $>0.07$, so Eq. 7.8 is appropriate. The partial pressure of the impurity at the end of the segment, $P_{d}$, is

$$
P_{d}=P_{c}+(R / W) P_{S},
$$

Substitute for R from Eq. 7.8

$$
P_{d}=P_{c}+-3.66 /(\operatorname{Re} S c) j\left(P_{b}-P_{c}\right) .
$$


Substutu for the huyolds and schmidt numbers then

$$
z_{3}=P_{a}+-3.00 D \cdot V d^{*}\left(P_{b}-P_{c}\right) . \quad 7.12
$$

As a particular asample, suppose that the partial pressure at the ancrance

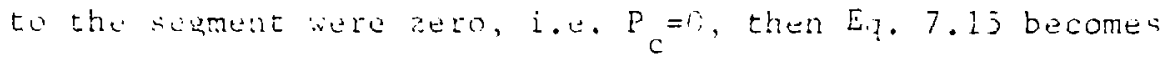

$$
\mathrm{P}_{\mathrm{d}}=(3.66 \mathrm{D} / \mathrm{Vd}) \mathrm{P}_{\mathrm{b}} \quad 7.13
$$

If we consider slower and slower flows through the same segment, this equation predicts that the partial pressure at the exit from the segment increases without limit, i.e. If $v_{0}$ then $P_{d}{ }^{-\infty}$. Phyically, this cannot happen. Evaporation only occurs if the partial pressure is less than the sacurated vapour pressure, and so the partial pressure at the exit to the segment must bu alvays less than the saturated vapour pressure.

The contradictions revealed by these tro examples are due to the inconsistent use of Eqs. 7.2 and $7.3-5$.

Develooment of an expression for mass transfer using the standard approach

We $:$ ill now develop the expressions for the evaporation or condensation rate following the usual approach adopted in the literature. The discussion will be based primarily on two books: 'Transport Phenomena, 20 by R. B. Bird, iv. E. Stewart and E. N. Lightioot and 'Mass Transfer'21 by T. K. Sherwood, R. L. Pigford and C. R. Willie. The latter book is a revision of the boor which was cited by Schwartz et. al. ${ }^{2}$ in the description of SORS. Expressions for the rate of mass transfer are often chosen on the basis of the analogies between mass, heat and momentum transfer, if the theoretical bases and experimental data for mass transfer are not available. $\because$ quote from 'Mass Transfer" page 150: "The close similarity of the processis of nass, heat and momentum transfer in fluids is 
suggestad by the fact that the basic equations axpressing the fluxes hay the same corm. . . . The similarity of the forms of the three rate aquations makes it possible to apply an analysis ot one of the srocesses to either ": the other tio." Table 21.2-1 of 'Transport Phunomena' gives a Iist or the analogous heat transier and binary mass transfer guantities: for example the Prandtl number in heat transier is the analogue of the Schmidt number in mass transfer.

We will define a transer coefficient and Nusselt number following section 21.1 of 'Transport Phenomena'. Consider a gas flowing along a nass transfer suriace through which an imourity may enter the stream at a local rate, $N$ moles/(unit area)(unit time). The diffusional contribution to.$N$ should be roughly proportional to some characteristic composition difference between the gas at the surface and in the main stream. Since we are considering a gas, it is convenient to use the difference in partial pressure of the impurity rather than the molar concentration. For a surIace of area $A$, we can define an average rass transfer coefficient, $\ddot{r}$, by the equation

$$
R(t)=\therefore\left(1 P ; P_{S}\right) A
$$

where $R(t)$ is the molar rate of transier across the whole surface in mole/sec,

A is the area of the surface in $\mathrm{cm}^{2}$,

$\Delta P$ is a characteristic difference in the partial pressure of the impurity (in atm),

$P_{S}$ is the pressure of the flowing gas (in atm),

$r i s$ an average mass transfer coefficient in moles; (sec $\mathrm{cm}^{2}$ ). 
$P_{\text {s }}$ should be multiplied by a correction Eactor. Since this correction iactor is approx mately equal to one for low impurity concentrations, ye shall, for simplicity, omit the factor here. The same ractor was onitted in the pravious section. The characteristic pressure difference, ip, nay be defined in several difierent ways, leading to correspondingly different definitions of the mass transfer coefficient ' $r$. For example ip may be defined as the initial difference in partial pressures; alternatively, $\Delta P$ may be defined as an arithmetic, or logarithmic, average over the whole surface, of the difference in partial pressures. If the transfer rate is "ery small these three definitions of $\triangle P$ vould give the same value for the mass transer coefficient $\therefore$. However at high transfer rates, there may be a considerable difference between the different choices for $\therefore$. An example, For the case of heat transfer, is shown in Fig. 13.1-3 of 'Transport Phenomena'. In practice, the logarithmic average is usually adr ited. It is useful to proceed in terms of a dimensionless number, the Nusselt number, which is derived from $k$. The Nusselt number, Nu, for Ilow through a circular tube, is defined as

$$
\therefore u=\frac{k d}{c D}
$$

where $\mathrm{d}$ is the diameter in $\mathrm{cm}$,
$c$ is the molar concentration in moles $/ \mathrm{cm}^{3}$,
$D$ is the binary difrusion coefficient in $\mathrm{cm}^{2} / \mathrm{sec}$.

Since the Nusselt number derives from the transfer coefficient, there is a local Nusselt number, a logarithmic Nusselt number, etc. We can rewrite Eq. 7.14 in terms of the Nusselt number, and the area of a segment, 
of length Lcm, of a circular channel. The molar rate of tiansfer for the segment is

$$
R(t)=C D N u \pi L\left(J P / P_{s}\right)
$$

To facilitate comparison with the expressions used in SORS we will rewrite this expression so that it involves the flow rate of the carrier gas, $W$, explicitly.

$$
W=c V \pi d^{2} / 4
$$

where $W$ is the carrier gas flow rate (moles/sec),

$c$ is the density of the carrier gas (moles/ $\mathrm{cm}^{3}$ ),

d is the diameter of the channel (cm),

$\mathrm{V}$ is the average velocity of the carrier $\mathrm{gas}(\mathrm{cm} / \mathrm{sec})$.

In terms of the Reynolds and Schmidt numbers

$$
W=T c \operatorname{cd} \operatorname{ReSc} / 4
$$

Substituting in Eq. 7.16, the molar rate of transfer for a segment is

$$
R(t)=(4 \mathrm{~L} / d)(\mathrm{Nu} / \mathrm{Re} \mathrm{Sc})\left(\mathrm{W} \Delta \mathrm{P} / \mathrm{P}_{\mathrm{S}}\right)
$$

'Transport Phenomena' quotes expressions for the logarithmic heat transfer Nusselt number for three flow regimes on page 399 and page 404. These expressions are based on theory and experimencal data. If we substitute the analogous quantities for mass transfer we obtain the following equations for the logarithmic mass transfer Nusselt number, ${ }^{N u}{ }_{1 n}$,

For $\operatorname{Re}>20,000$

$$
\mathrm{Nu}_{\text {In }}=.026 \mathrm{Re}^{0.8} \mathrm{Sc}^{.33}
$$

For $\operatorname{Re}<2000$ and $\mathrm{I} /\left(\mathrm{d} \operatorname{Re} \mathrm{Sc}_{\mathrm{c}}\right)<.1$

$$
\mathrm{Nu}_{\text {In }}=1.86(\mathrm{~d} / \mathrm{L} \operatorname{Re} \mathrm{Sc})^{1 / 3}
$$




$$
\begin{aligned}
& \text { For Re } \therefore 200 \mathrm{l} \text {, Nu } 1 n \text { tends to a } 1 \text { imit for large values of ( } / \mathrm{d} \text { Re Sc) } \\
& \operatorname{Lim} \operatorname{Nin}_{1 \mathrm{n}}=3.657 \quad 7.22
\end{aligned}
$$

Shervood et. al. ${ }^{19}, 21$ discuss the experimental data on mass transfer, between the surface of a liquid film and a gas stream in a vetted wall column, for turbulent flow, $\operatorname{Re}>2000$. They quote several empirical relationships similar to Eq. 7.24 but with slight variations in the choice of the multiplicative factor and the exponents. So it is reasonable to use Eq. 7.24 Eor flow rates such that $\operatorname{Re}>2000$.

We can now combine Eq. 7.19 with the empirical expressions given in Eqs. $7.20-22$.

$$
\begin{aligned}
& \text { EOr Re }>200 r \\
& R(t)=(4 \mathrm{Ld})\left(.026 /\left(\mathrm{Re}^{0.2} \mathrm{Sc}^{.67}\right)\right)\left(\mathrm{W} \Delta \mathrm{P}_{1 \mathrm{n}} / \mathrm{P}_{\mathrm{s}}\right) \\
& \text { Eor } \operatorname{Re}<200 \mathrm{C} \text { and } \mathrm{L} / \mathrm{d} \operatorname{Re} \mathrm{Sc}_{\mathrm{c}}<.1 \\
& R(t)=(\mathrm{rL} / \mathrm{d})\left(1.86(\mathrm{~d} / \mathrm{L} \operatorname{Re} \mathrm{Sc})^{1 / 3} / \operatorname{Re} \mathrm{Sc}\right)\left(\mathrm{W} \Delta \mathrm{P}_{1 \mathrm{n}} / \mathrm{P}_{\mathrm{S}}\right) \quad 7.24
\end{aligned}
$$

We emphasize that since Eqs. $7.20,7.21$ refer to logarithmic Nusselt numbers, the pressure differences in Eqs. 7.23 and 7.24 must also be logarithmic averages. This difference is academic only for a flow rate and length of segment such that $\Delta P$ does not change much along the length of the segment. For the third possibility which corresponds to slow flow rates and a long segment, the limiting value of $\mathrm{Nu}_{1 \mathrm{n}}$ must be used. However this limit must be treated consistently, since the logarithmic pressure difference diverges, so we will expand on this case in more detail.

For brevity, we will introduce a dimensionless number which we will 
call the "stagnation number", sn,

$$
\mathrm{Sn}=\mathrm{Lid} \operatorname{Re} \mathrm{Sc}
$$

where $L$ is the length of the segment,

$d$ is the diameter of the channel,

Re is tixe Reynolds number,

Sc is the Schmitt number.

The stagnation number can be rewritten as a ratio of the time that the coolant takes to traverse the channel to the time that an impurity atom. takes to diffuse from the wall to the center of the channel. The reason for calling this dimensionless quantity the stagnation number is apparent as it measures the degree of stagnation of the flow. In a stagnant container an impurity in the fluid will be in equilibrium with the impurity deposited on the walls of the container. For flow through a channel, if the stagnation number is large there is ample time for many atoms to diffuse into the coolant stream during the time the coolant takes to flow the length of the channel. So at the exit from the channel the construction of an impurity in the coolant will be in quasi-equilibrium with the impurity on the walls of the channel. For the case under consideration the driving force for mass transfer is the difference between the partial pressure of an impurity in the coolant and the vapour pressure of the impurity at the temperature of the graphite. How close the partial pressure, at the exit of a segment, is to the vapour pressure, within the segment, depends on the value of the stagnation number. Fig. $7.2^{19}$ shows some data and theoretical predictions for flow through tubes. The pressure at the exit of a segment tends to the stagnant limit for large values 
of the stagnation number and is within $5 \%$ of the limit for values of the stagnation number greater than about 0.2 .

The limiting case tor slow flows corresponds to a logatithmic Nusselt numbe: equal to about 3.66 and a pressure at the exit to the segment approximately equal to the vapour pressure. The correct limiting form for the total number of moles transferred per second in a segment is equal to the difference between the number of moles leaving the segment per second at a partial pressure equal to the vapour pressure, $P_{b}$, and the number of moles entering the segment per second at a partial pressure $P_{c}$. Assuming that we can use the perfect gas laws for both coolant and impurity

$$
\frac{W}{P_{S}}=\frac{R(t)}{P_{b}-P_{c}}
$$

or For $\operatorname{Re}<2000$ and $\mathrm{L} / \mathrm{d} \operatorname{Re} S_{c}>.2$

$$
R(t) \approx W\left(P_{b}-P_{c}\right) / P_{S}
$$

To sumarize, the pertinent equations which should be used to calculate mass transfer are Eqs. $7.23,7.24$ and 7.27 . These can now be compared with those used in SORS, Eqs. $7.6,7.7$ and 7.8 .

Comparing Eqs. 7.23 and 7.24 with Eqs. 7.6 and 7.7 , we notice two differences. A geometrical factcr $4 \mathrm{~L} / \mathrm{d}$ is omitted from the equations used in SORS. Also the pressure difference at the entrance to the segment is used instead of the logarithmic average pressure differences. Comparing Eqs. 7.27 and 7.8 we see that an extra factor ( $3.66 /$ Re Sc) has been included in the expression used in SORS. Application to the hypothetical accident

We will now apply the previous discussion to the hypothetical 
accident under consideration. The accident scenario assumes that there is no forced circulation and so the coolant flow is induced by natural convection. Using the code RECA, ${ }^{12}$ Schwartz et. al. estimated that the average Reynolds number varies from 6.9 at 1 hour to .0041 at 50 hours. Because of the difierences in temperature the Reynolds number varies irom one part of the core to another and also with time. For the flow rate of $5.67 \times 10^{3} \mathrm{gm}$ mole/hr, which is used in the sample data supplied by General Atomic, the ranges of Reynolds number in the core are shown in Table 7.1 . In other published data ${ }^{6}$ a flow rate of $5.67 \times 10^{5} \mathrm{gm} \mathrm{mole/hr}$ is used. This would increase the Reynolds number by a factor of 100 . For the trial data the Reynolds numbers vary from.1 to .5, so the flow is laminar. The second dimensionless number is the Schmidt number. Values of this number range from .18 to 1.8. Table 7.1 shows the range of values of the stagnation number calculated in SORSG using the trial data. Sn varies from 247 to 2500. Even if the flow rate is increased by a factor of 100 the stagnation number is still within the limiting regime. Thus, for the flow conditions expected during the accident, the rate of transfer from coolant to the graphite and vice versa should be based on the expressions for the st.agnant limit, Eq. 7.27 .

The expression used for $R(t)$ in SORSG, Eq. 7.8 , contains an erroneous factor equal to $(3.66 / \operatorname{Re} S c)$. The implications of this on the further calculations cannot be predicted. For example, with the trial data supplied with the code SORSG, a typical value of this factor is about 10 . Thus in one portion of the core the code will overestimate the rate of evaporation by a factor of 10 , yet in another portion of the core, where 
mas transier is ir the opposice direction, the cowe will overestimate the tmounc depositad back on the surtace by a factor of 10. So the ner effect of the error on the reluase rate of a fission product from the core is unrodictable. To sea what the effect may be, the instructions in the code SORSi in wirich the evaporation rate was calculated, were changed from Eq. 7.5 to Eq. 7.7. The rest of the structure of the code was unchanged. Fig. 7.3 shows the output using the trial data supplied by GA for the two calcu1acions. The release curve is shifted by about 10 hours for ${ }^{90} \mathrm{Sr}$.

EFect of correlacions between the time of the release from the fuel and the evaporation rate

As discussed in Chapter 4, the code is structured in such a way that the total amount of a fission product which has escaped from the fuel particles, is used as the source term for diffusion and evaporation. In other words the correlation between the release from the fuel particles in a given segment and the diriusion and evaporation within the same segment, is neglected. This approximation is only good if the migration rate through the graphite is low at the temperatures at which the material is released from the fuel. To see the possible significance of this correlation the code, modified as described previously to use Eq. 7.7 , vas run ivith the amount in the graphite at the start of the accident equal to $0 \%, 10 \%$ and $100 \%$. Fig. 7.4 shows the release curves for ${ }^{90} \mathrm{Sr}$. The three curves are close to each other and so the time at which ${ }^{90} \mathrm{Sr}$ is released from the fuel does not affect appreciably its migration through the graphite for this set o data. Comparison of the resuits of SORSG with the results of EVAP Subroutine RELEAS calculates the release rate from the graphite in 
adh section of the core and alculates a : aveage of the rolease ratei ror the whole core. RELEAS is called at specilied time intervals. The anount of an elament within the graphite of a given section is expressed as the product of the toral amount of the elenent in the graphite of the whole reactor and a veighting Eactor for the particular section. The change in the veighting factor is calculated within subroutine RELEAS. However the change in the total amount of a fission product in all of the graphite of the reactor is calculated in the main part of the program, using the average release rate from the graphite and including radioactive decay. This mathematical procedure could conceivably introduce some inaccuracies into the results.

An independent code EVAP was written to produce results which could be compared with the results of SORSG under appropriate conditions. A decailed description of EVAP is given in a report. 22 In EVAP the core is divided into several sections as in SORSG. EVAP calculates only the migration along the coolant channels, it does not calculate the release from the fuel particles, the rate of diffusion or decay. It is assumed that the concentration of an impurity is uniform within each of the graphite sections. EVAP treats each radial region of the core separately. For one radial region, the coupled differential equations for the amount of an impurity within each of the sections of that region are integrated numerically from the start of the accident to the final time desired. The same procedure is followed for each of the racial regions in turn. The total amount released from the whole core is the sum of the amounts released from each radial region. 
For illustration we show the results for cino stable isotopes, Fib. i.j compares the resules cor ${ }^{88} \mathrm{Sr}$ and ${ }^{149} \mathrm{Sm}$ calculated by SORSG, modizied as describud previously, and With. Fur Sr there is a smali difierence in the two curves. SORSG predicts that $149 \mathrm{Sn}$ nouid be released about 20 hours earlier than is predicted by EVAP. SORSG predicts that at 20 hours after the initiation of the accident about $4.3 \%$ of the ${ }^{149} \mathrm{Sm}$ would be released. Ne will make a rough estimate of an upper bound for the maximum release during the first 20 hours, using a crude and overly conservative model. Assume that all the ${ }^{149} \mathrm{Sm}$ is initially in the upper half of the top reflector. The highest temperature reached in the upper half of the ton reilacor by 21 hours is $2621^{\circ} \mathrm{c}$. At this temperature the vapor pressure of Sm would be $4.5 \times 10^{-5} \mathrm{~atm}$. The temperature of the upper half of the top reflector rises slowly during the course of the accident. For the purposes of this calculation assume that the temperature is equal to $2621^{\circ} F$ for 20 hours. Taking the same flow rate used in SORSG the computed amount of ${ }^{149} \mathrm{Sm}$ which can be swept out of the reflector in 20 hours is ajout $1.5 \%$. The difference betveen the $4.3 \%$ computed by SORS and the upper Dound of $1.5 \%$ indicates that the mathematical procedure adopted in SORSG could introduce inaccuracies, and further analysis of the algorithms in SORS is needed to identiry the source of the discrepancy. VIII. Summary of Observations

The objective of the code SORS is to calculate the release of fission products from the fuel into the primary coolant circuit. The code calculates the release from the fuel particles and uses this release as a source tarm for the second stage of migration. The only physical 
processes considered in the second stage are difrusion and evaporation.

The problem involves a consideration of three kinetic processes inulEaneously. radicactive decay, transport out of the fuel, and transport through the graphite and in the primary coolant. The two transport rates depend both on time and on the position within the reactor, since these rates involve processes which are temperature dependent. A mathematical solution of the problem must incorporate two features, a subdivision of the core into segments and a technique for the numerical integration of the differential equations. The approach adopced in soRs is to calculate average reactor wide values for the transport rates by solving, approximately, differential equations, which neglect decay, in each segment of the core. Then the differential equations for the vhole reactor incorporating both decay and the average values of the transport rates, are integrated using an accurate and sophisticated numerical technique. A simultaneous treatment of decay and transport is required only if the rates of these tivo processes are comparable. If the changes caused by decay are negligible then the accuracy of the final solution is determined by the averaging process, that is by the subdivision of the core and the time interval and integration technique used in calculating the changes within each segment. To repeat the integration, as done in SORS, does not increase the accuracy. If the rates of decay and transport are comparable, the procedure used in SORS to decouple these processes is questionable. The average values of the transport rate are calculated by neglecting decay in each individual segment, this neglect of one of two comparable terms in a differential equation introduces a large approximation. To 
rantegrace the ruacor vide difierential equations, which incorporate borh decay and the approximate values for the average transport rates, does not compensate for any ezro:s, wich may have been introduced in the calculacion of the average cransport rates.

1) Release Erom the fuel particles

The results from SORS are as accurate as the results calculated in FKCALC, wherein a time step of about 1.5 hours has been used. The interpretation of the experimental data on the properties of the fuel particles, is one of the most important inputs to the code. A very crude calculation with one core segment and a time step of 1.5 hours gives a fair approximation, in most cases, to the results calculated using the whole code. The differences between the results based on different fuel models are large. The temperature distribution and evolution is another important set of input data.

2) Iransport through the graphite and in the coolant channels

1. The release from the fuel and the second stage of transport have been decoupled. The adequacy of this approximation depends on the transport rates at the temperatures at which release from the fuel occurs. For ${ }^{90} \mathrm{Sr}$ the time at which the atoms escape from the fuel particles does not appear to affect the release into the coolant.

2. For this stage the calculation of an average transport rate and the integration of the averaged reactor wide equation proceed in parallel. The reintegration cannot improve the accuracy 
over that attained in subroutine RELEAS, moreover this alteration may introduce additional errors. For example, the amount of a fission product in the graphite in a given segment is written as the product of the cotal amount in the graphite for the whole reactor and a weighting factor. The first term in this product is affected by what has happened in other segments of the reactor, far away from the segment under consideration. A comparison with a code which treats the migration along the coolant channels in a different manner shows that, for the conditions considered, the release curves may be displaced a few hours.

3) The expression used to calculate the evaporation rate is in error. This error introduces inconsistencies during the course of the calculation. The net effect of the error is indeterminate since the net evaporation rate is overestimated in some parts of the core and underestimated in other parts.

\section{Conclusions}

1) The calculation scheme for the release of the volatile fission products is probably adequate. The mathematical accuracy is determined primarily by the time step used in subroutine FKCALC. The accuracy of the results is dominated by the uncertainties in the experimental data, in the empirical model for release from the fuel particles and in the temperature history.

2) Assuming that the expression for the evaporation rate and for the mass transfer coefficient are made consistent, the results predicted by SORSG using the trial data differ slightly from the 
results predicted by another independent code. Ne attribute these differences to the mathematical procedure used in the SORSG to average over tht: core and to include decay. For the nonvolatile Eission products the accuracy of the results is dominated by uncertainties in the temperature history of the top reflector, the flow rate of the coolant and the vapour pressure data.

Any calculations based on the code, in the form which we received it and using the expressions described in LTR-10 ${ }^{2}$ for the evaporation rate are incorrect. The magnitude of the error depends on the conditions specified for the accident and may be 1arge.

Acinowledgements

I thank J. Beerman and J. Colman for their help in using the CDC 7600 and the scope operating system and L. G. Epel for several interesting discussions about SORS. I would also like to express my appreciation to Grace Searles and Jacqueline Mooney for typing this paper. 


\section{REFERENCES}

1. $10 C F R$ 10i.11.

2. Y. H. Schwartz, D. B. Sedgeley and M. M. Mendonca, "SORS: Computer Programs for Analyzing Fission Product Release irom HTGR Cores During Transient Temperature Excursions," Gi-A12462, 1974, and supplements.

3. K. E. Schwartztrauber and F. A. Silady, "CORCON: A Program for Analysis of HTGR Core Heatup Transients," GA-Al2868, 1974.

4. Fort St. Vrain Nuclear Generating Station, Unit 1, Final Safety Analysis Report, Public Service of Colorado, USAEC Docket No. 50-267.

5. Fulton Generating Station Preliminary Safety Analysis Report, Philadelphia Electric, USAEC Docket No. 50-256, 1973.

6. "GASSAR-6," General Atomic, GA-A13200, 1975.

7. "HTGR Accident Initiation and Progression Analysis Report," General Atomic, GA-Al3617, 1976.

8. A. Badur, K. Kasper, A. Yueller, C. Schwartzer and J. Wolters, "Consequences of Ultimate Sequences of HTGRs," Trans. American Nuclear Society 26,316 (1977).

9. F. E. Vanslager, "RAD2: A Computer Program for Calculating Fission Product Radioactivities," GND-6519, 1965.

10. C. J. Hamilton, "HTGR Power Distributions," GA-A13007, 1974.

11. D. I. Macnab, "The CONTEMPT-G Computer Program and Its Application to HTGR Containments," GA-A12692, 1974.

12. H. W. Chi and G. J. Malik, "Description of the Reactor Emergency Cooling Analysis Code, RECA," GA-10273, 1970.

13. C. L. Smith, "Fuel Particle Behavior Under Normal and Transient Conditions," GA-A12971, 1974.

14. M. Tokar, "Evaluation of HTGR Fuel Particle Coating Failure Models and Data," NUREG-0111, 1976.

15. M. T. Morgan, "Review of HTGR Coated Fuel Particle Stability," ORNL-TM-4882.

16. J. H. Norman, "Review of Vapor Pressures and Diffusion Coefficients of Certain HTGR Core Vaterials and Fission Products for Use in Reactor Accident Calculations, GA-A12634. 
17. J. D. Lambert, Computational Yethods in Ordinary Differential Equations, John Wiley \& Sons, 1973.

18. J. Crank, The Mathematics of Diffusion, Oxford University Press, 1975.

19. T. K. Sherwood and R. L. Pigford, Absorption and Extraction, McGraw Hill, 1952.

20. R. B. Bird, W. E. Stewart and E. N. Lightfoot, Transport Phenomera, John Wiley \& Sons, 1960.

21. T. K. Sherwood, R. L. Pigford and C. R. Walke, Mass Transfer, McGraw Hill, 1975.

22. J. M. Dickey, "The Migration of the Fission Products Along the Coolant Channels of a High Temperature Gas Cooled Reactor Following a Hypothetical Accident of Complete Loss of Cooling," BNL-NUREG, 1978 (in press). 


\section{Table 3.1}

Fission Proauct Classification by Chemical and Thermodynamic Similarities

\begin{tabular}{|c|c|}
\hline $\begin{array}{l}\text { Species } \\
\text { Number }\end{array}$ & Element \\
\hline 1 & Sr \\
\hline 2 & $\mathrm{Rb}, \mathrm{Cs}$ \\
\hline 3 & $\mathrm{Ba}, \mathrm{Sm}, \mathrm{Eu}$ \\
\hline 4 & $\mathrm{Ce}$ \\
\hline 5 & Xe \\
\hline 6 & $\mathrm{Kr}$ \\
\hline 7 & $\mathrm{Zr}, \mathrm{Nb}, \mathrm{MO}, \mathrm{Te}$ \\
\hline 8 & $Y, P d, S n, L_{a} a, P \delta: N d, P m$ \\
\hline 9 & $\mathrm{Ru}, \mathrm{Rh}$ \\
\hline 10 & Se, $\mathrm{Br}, \mathrm{Te}, \mathrm{Sb}, \mathrm{I}$ \\
\hline
\end{tabular}


Table 3.?

\begin{tabular}{llr} 
Diffusion Coeficients for Elements in Graphice (a) \\
Element & \multicolumn{1}{c}{$\mathrm{A}$} & \multicolumn{1}{c}{$B$} \\
\hline $\mathrm{Y}$ & 0.74 & 14.2 \\
$\mathrm{Zr}$ & 1.19 & 22.8 \\
$\mathrm{Nb}$ & 1.32 & 25.5 \\
$\mathrm{Vo}$ & 1.00 & 19.2 \\
$\mathrm{Tc}$ & 1.02 & 19.6 \\
$\mathrm{Ru}$ & 0.91 & 17.5 \\
$\mathrm{Rh}$ & 0.77 & 14.8 \\
$\mathrm{Pd}$ & 0.52 & 10.1 \\
$\mathrm{Sb}$ & 0.35 & 6.8 \\
$\mathrm{La}$ & 0.75 & 14.4 \\
$\mathrm{Ce}$ & $0.84(0.55)$ & $16.2(10.5)$ \\
$\mathrm{Pr}$ & 0.63 & 12.0 \\
$\mathrm{Nd}$ & 0.56 & 10.7 \\
$\mathrm{Pm}$ & 0.44 & 8.5 \\
$\mathrm{Sm}$ & 0.39 & 7.6 \\
$\mathrm{Eu}$ & 0.33 & 6.4 \\
$\mathrm{Th}$ & $1.03(0.98)$ & $19.8(18.8)$ \\
$\mathrm{Pa}$ & 1.13 & 21.7 \\
$\mathrm{U}$ & 0.81 & 15.6 \\
$\mathrm{Pu}$ & 0.55 & 10.6 \\
$\mathrm{Sr}$ & $0.34(0.67)$ & $6.5(6.8)$ \\
$\mathrm{Ba}$ & $0.35(0.12)$ & $6.7(7.0)$ \\
$\mathrm{Cs}$ & 0.21 & 4.1 \\
$\mathrm{Rb}$ & 0.21 & 4.1 \\
\hline & &
\end{tabular}

(a) Literature values are shown in parentheses.

$-\log _{10} D=A+\frac{B \times 10^{3}}{T}$,

where $D$ is in $\mathrm{cm}^{2} / \mathrm{sec}$ and $T$ is in ${ }^{\circ} \mathrm{K}$

(source: Ref. 16).

Table 3.3

Freundich Isotherms of Certain Fission Products (a)

\begin{tabular}{lllll} 
Element & $\mathrm{a}$ & $\mathrm{b}$ & & \\
\cline { 2 - 3 } $\mathrm{na}$ & 6.49 & -33.7 & -1.304 & 7.55 \\
$\mathrm{Sr}$ & 8.67 & -36.1 & -0.572 & 4.59 \\
$\mathrm{Cs}$ & 7.8 & -29.84 & 0.2351 & 1.873 \\
$\mathrm{Rb}$ & 9.33 & -31.06 & -2.23 & 6.99 \\
\hline
\end{tabular}

(a) $\ln P_{m}=a+\frac{b \times 10^{3}}{T}+\left(c+\frac{d \times 10^{3}}{T}\right) \ln c_{m}$

where $P_{m}$ is in atm and $C_{m}$ is in $\mu$ moles $/ m^{2}$ reactor graphite surface area (source: Ref. 16). 
Table 3.4

Vapor Pressures of Elements in a Graphice System (a)

\begin{tabular}{|c|c|c|c|c|c|}
\hline$P_{n}$ & $A$ & B & $P_{n}$ & $A^{\prime}$ & $B^{\prime}$ \\
\hline Y & 4.21 & 25.8 & $\mathrm{Ce}$ & 6.77 & 29.5 \\
\hline $\mathrm{YC}_{2}$ & 8.70 & 39.3 & $\mathrm{CeC}_{2}$ & 9.83 & 36.7 \\
\hline $2 r$ & 7.65 & 41.5 & $\mathrm{Pr}$ & 4.37 & 21.9 \\
\hline $2 \mathrm{rC}_{2}$ & 9.40 & 49.4 & $\mathrm{PrC}_{2}$ & 7.58 & 31.3 \\
\hline Nb & 8.14 & 46.3 & Nd & 3.47 & 19.5 \\
\hline $\mathrm{NbC}_{2}$ & 9.88 & 54.6 & $\mathrm{NdC}_{2}$ & 7.00 & 30.4 \\
\hline Mo & 7.40 & 34.9 & Pm & 3.93 & 15.5 \\
\hline Tc & 8.09 & 35.6 & Sm & 3.72 & 13.8 \\
\hline$R u$ & 7.27 & 31.9 & Eu & 3.28 & 11.6 \\
\hline RuC & 7.97 & 34.9 & $\mathrm{EuC}_{2}$ & 6.66 & 26.2 \\
\hline $\mathrm{Rh}$ & 6.85 & 26.9 & Th & 6.40 & 36.0 \\
\hline RhC & 7.87 & 32.4 & ThC $_{2}$ & 7.86 & $39 . '$ \\
\hline $\mathrm{Pd}$ & 5.59 & 18.2 & $\mathrm{~Pa}+\mathrm{PaC}_{2}$ & 6.99 & 39.2 \\
\hline $\mathrm{Sb}$ as $\mathrm{Sb}$ & 5.35 & 12.4 & $\mathrm{U}$ & 4.50 & 28.3 \\
\hline Sb as $\mathrm{Sb}_{2}$ & 5.13 & 9.0 & $\mathrm{UC}_{2}$ & 7.89 & 38.7 \\
\hline $\mathrm{Sb}$ as $\mathrm{Sb}_{4}$ & 2.60 & 5.1 & $\mathrm{Pu}$ & 3.45 & 19.3 \\
\hline La & 5.16 & 26.1 & $\mathrm{PuC}_{2}$ & 5.20 & 30.0 \\
\hline $\mathrm{LaC}_{2}$ & 7.81 & 33.3 & & & \\
\hline
\end{tabular}

(a) $\log P_{n}=A-B \frac{10^{3}}{T}$, where $P_{n}$ is in atm and $T$ is in ${ }^{\circ} K$ (source: Ref. 16). 
Table 3.5

Monolayer Concentrations in Graphite

(graphite assumed to have $1 \mathrm{~m}^{2} / g$ surface area and a $90.7 \%$ packing fraction allowed)

\begin{tabular}{lc} 
Element & $\begin{array}{c}\text { Monolayer Concentration } \\
\text { (umoles/g graphice) }\end{array}$ \\
\cline { 2 - 2 } $\mathrm{Rb}$ & 7.8 \\
$\mathrm{Sr}$ & 10.4 \\
$\mathrm{Y}$ & 15.1 \\
$\mathrm{Zr}$ & 18.7 \\
$\mathrm{Nb}$ & 22.5 \\
$\mathrm{No}$ & 24.9 \\
$\mathrm{Tc}$ & 25.9 \\
$\mathrm{Ru}$ & 26.7 \\
$\mathrm{Rh}$ & 26.7 \\
$\mathrm{Pd}$ & 25.6 \\
$\mathrm{Sb}$ & 19.0 \\
$\mathrm{Cs}$ & 6.7 \\
$\mathrm{Ba}$ & 9.7 \\
$\mathrm{La}$ & 13.7 \\
$\mathrm{Ce}$ & 14.6 \\
$\mathrm{Pr}$ & 14.5 \\
$\mathrm{Nd}$ & 14.5 \\
$\mathrm{Pm}$ & 14.6 \\
$\mathrm{Sm}$ & 14.6 \\
$\mathrm{Eu}$ & 12.1 \\
$\mathrm{Th}$ & 14.7 \\
$\mathrm{U}$ & 25.1 \\
$\mathrm{Pu}$ & 20.9 \\
\hline
\end{tabular}

(Source: Ref. 16) 
Table 6.1

Approximate Diffusion Times in Hours at the Stated Temperature for:

1. Release of a few percent

2. Attainment of an even concentration

3. Release of about a third

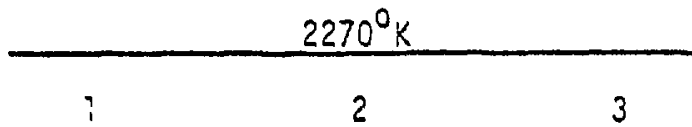

25

CS

EU

$S R$

SA

$S B$

$S M$

$P M$

PD

PU

V.

$P R$

$Y$

$L A$

RH

$\checkmark$

CE

RU

no

TC

TH

$P A$

$Z R$

NB
$1.75-03$

1.7E-03

$2.4 E-02$

2. $7 E-02$

3. $3 \Xi-0$ ?

3. $7 E-02$

9.: $E-02$

2. $5 E=01$

$1.6 E+00$

$2.8 E+00$

$3.1 E+00$

$1.4 E+01$

$1.6 E+02$

$2.1 E+02$

$3,2 E+02$

$8.0 \varepsilon+02$

$1.6 \vec{E}+03$

$6 \cdot 9 E+03$

$4.8 \varepsilon+04$

$7.5 E+04$

$9.4 E+04$

$8.2 E+05$

2. $9 E+06$

$6.0 E+07$
$1.95-02$

1. $9 E-02$

2. $5 E-0$ :

2. $9 E-01$

$3.6 \vec{\varepsilon}-01$

4. OE-0I

9. $9 \varepsilon-01$

ट. $8 E+00$

1. $7 E+01$

3. $0 E+01$

$3.4 E+01$

$1.5 E+02$

1. $8 E+03$

2. $25+03$

$3.5 E+03$

8. $7 E+03$

$1.7 E+04$

$7.5 E+04$

$5.2 E+05$

$8.2 E+05$

1. $0 E+06$

$\forall .3 E+06$

$3.1 E+07$

$6.5 E+08$
5. $0 E-02$

5.0 $0-02$

$0.7 \Xi-01$

$7.6 \equiv-01$

$4.6 E-01$

1. $1 \Xi+00$

2. $6 E+00$

$7 \cdot 3 E+00$

$4 \cdot 5 E+01$

$7.9 E+0 i$

9. $0 E+01$

3. $9 E+02$

$4.7 \overline{0}+03$

$5.9 E+03$

$9 \cdot 3 E+03$

2. $3 E+04$

$4.5 E+04$

2. $0 E+05$

$1.4 E+06$

2. $2 E+\cup 6$

$2.7 E+06$

2. $3 E+07$

$8 \cdot 2 E+07$

$1.7 E+09$ $3640^{\circ} \mathrm{K}$

2

3

$3.6 \Xi-04$

$3.6 \bar{E}-04$

2. $O E-03$

2. $2 E-03$

$2.6 E-03$

$2.8 E-03$

$5.0 E-03$

$9.9 E-03$

$3.3 E-02$

$4.8 E-02$

$5.3 E-02$

1. $4 E-01$

7. उE-01

8. $5 E-01$

1. $1 E+00$

$2.1 E+00$

$3.3 E+00$

$8.7 E+00$

3. $1 E+0 I$

4. $2 E+01$

4. $9 E+01$

2. $I E+02$

$4.7 E+02$

$3.5 E+03$
$3.95-03$

$3.9 \varepsilon-03$

Zे. $2 E-02$

2. $4 E-02$

C. $8 E-02$

3. $0 E-U 2$

5. $4 E-02$

I. $1 E-0 I$

3. $6 E-01$

$5.2 E-01$

$5.7 E-01$

1. $5 E+00$

$7.9 \vec{E}+00$

$9 \cdot 2 E+00$

l. $2 E+01$

$2.3 E+01$

$3.5 E+01$

$9.4 E+01$

$3.4 E+02$

4. $6 E+02$

$5.3 E+02$

$2.25+03$

$5.1 E+03$

$3.8 E+04$
1. $0 E-1]$

1. $0 E-02$

5. $95-02$

$6.4 \bar{E}-02$

$7.4 E-02$

7.9E-02

1. $4 E-01$

2. $8 E-0$ :

Y. $4 E-01$

i. $4 E+00$

1. $5 E+00$

4. $05+30$

2. $1 E+0$ :

2. $4 E+0 !$

3. $35+0$ :

6. $0 E+0$ :

Y. $3 E+0$ :

$2 \cdot 5 \equiv+02$

$9.0 \Xi+0 \hat{z}$

$1.2 E+03$

1. $4 E+03$

$5.9 E+03$

$1.4 E+04$

$\therefore 0 E+05$ 


\section{Table 6.2}

Nenperacure ( ${ }^{2}$ ) Required For Approximate Diffusion Times of One Hour and One DaY Assuming:

1. Rejease of a bew percent

$\therefore$ artainment uf an even concentration

3. Release of about a tinird
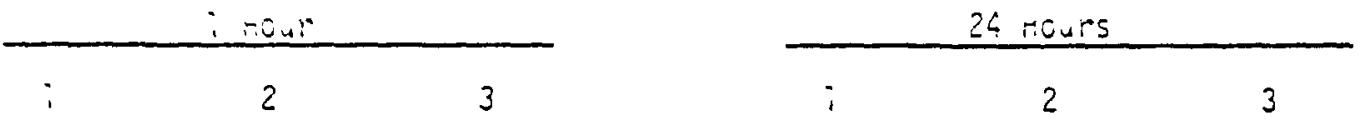

as

$: 556$

i529. $19: 3$.

is

$\therefore 56$.

$\therefore 629$.

19.3.

$2 \div 30$.

2925 .

3392 .

$3 \div 77$.

2978.

3465 .

2264.

3094.

3600.

2304.

3.47.

3660.

2658.

3620 .

4208.

$4: 72.405 i$.

3067.

6iv 3 i.

5ioc.

0426.

4053.

$55: 5$.

$65: 7$.

$4: 006$.

$554 i$.

7500.

781

781.

i527.

1551.

2617.

1648.

$19 i 2$.

2216.

2765.

2942.

$298 \mathrm{i}$.

3447.

4258 .

4333 .

4484 .

4791 .

5023 .

5542 .

6240.

6406 .

6490.

7308.

7801.

Table 7.1

Dimensionless Numbers in Coolant. Channel During Release of $\mathrm{Sr}$

Average

Reynolds Number

schmidt Number

Stagnation Number
$0.13=0.27$
$1.58-1.74$
$600-1400$
Mininum

0.1

0.8

247
1042.

1042.

1944.

1986.

2067.

2104.

2430.

2807.

3439.

$37: 2$.

$376 i$.

4347.

$537 i$.

5467.

5659 .

6050.

6340.

7016.

7921. $\therefore 284$.

i 184 .

¿i 76.

2223.

2312 .

2353.

2714.

3131. 3889. $4: 37$. $4 i 9 i$. 4846. 5493. 6101. 6317. 6757. 7093. 7849 . 
FISSILE COATEO FIEL PARTICLE

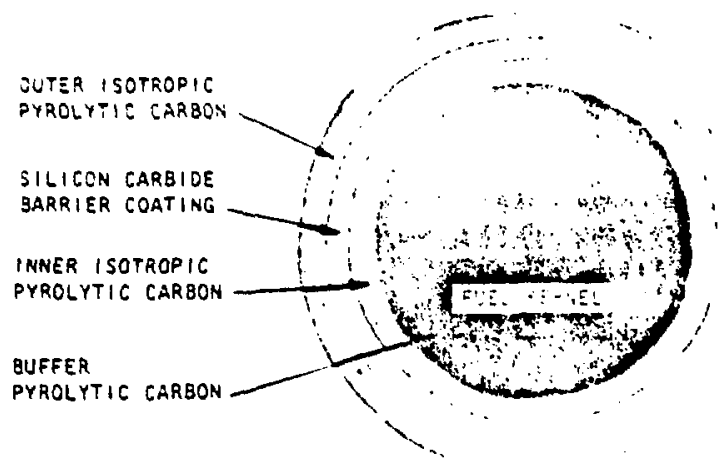

TRISO

\section{FERTILE COATED FUEL PARTICLE}

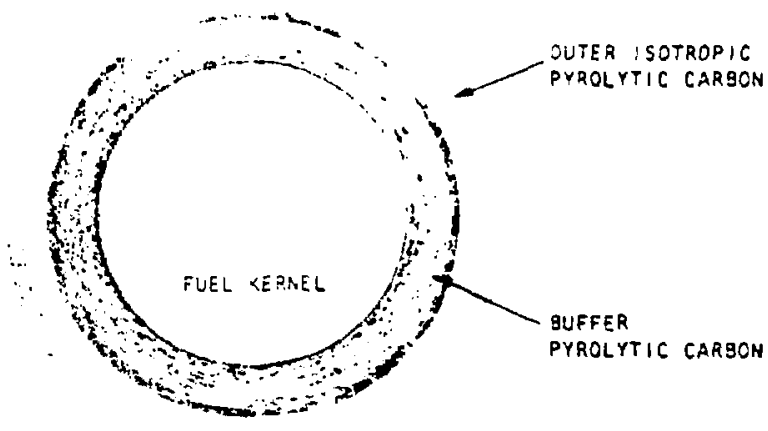

BISO

Figure 2.1. HTGR fuel particles. 


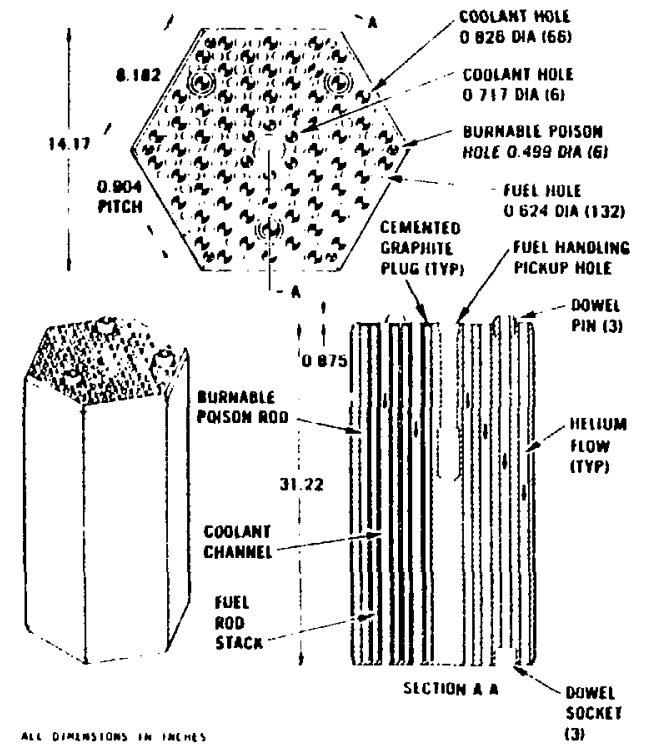

Figure 2.2. Large UTCR [uel element design. 2

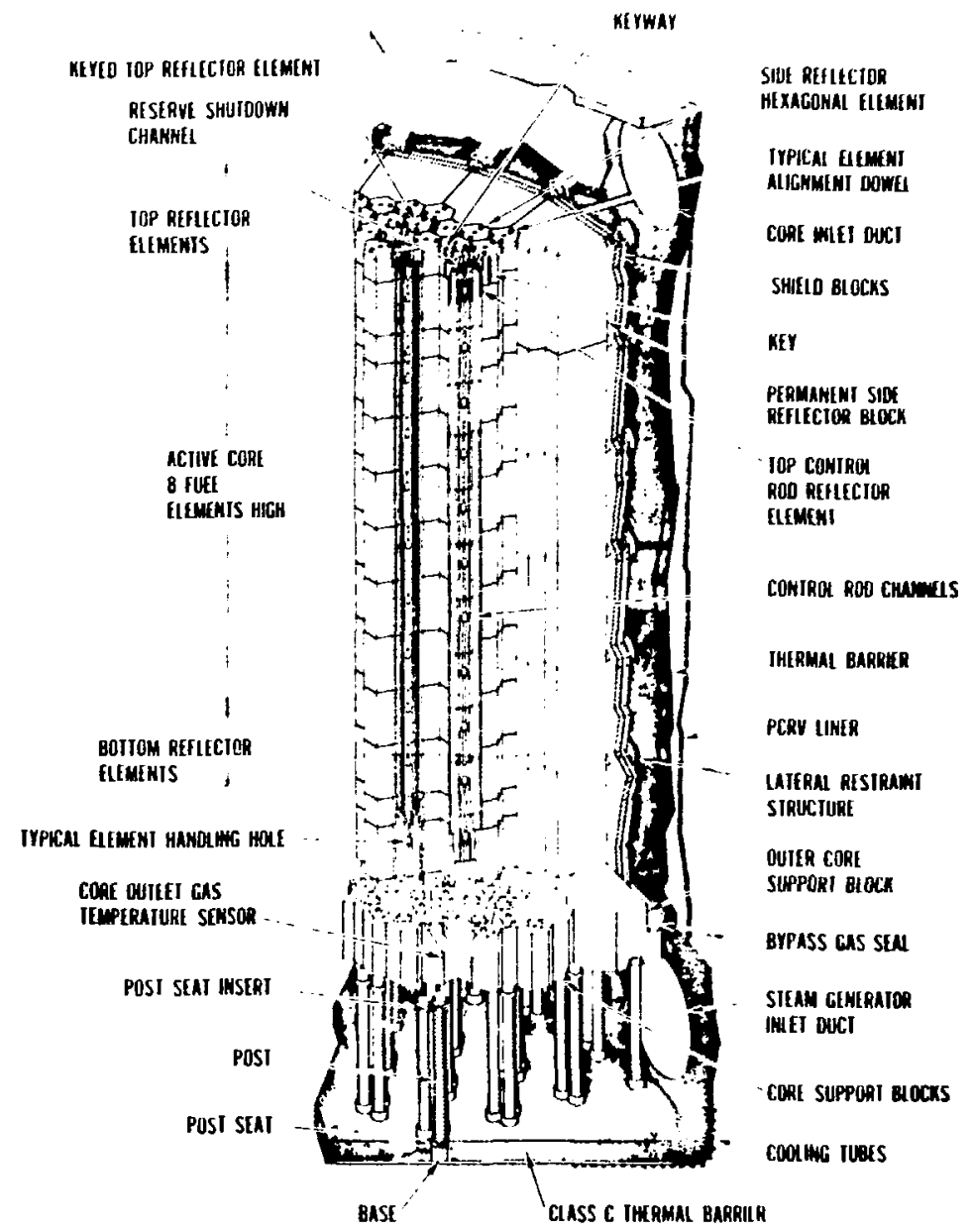

Figure 2.3. HTCR core and support artangement." 


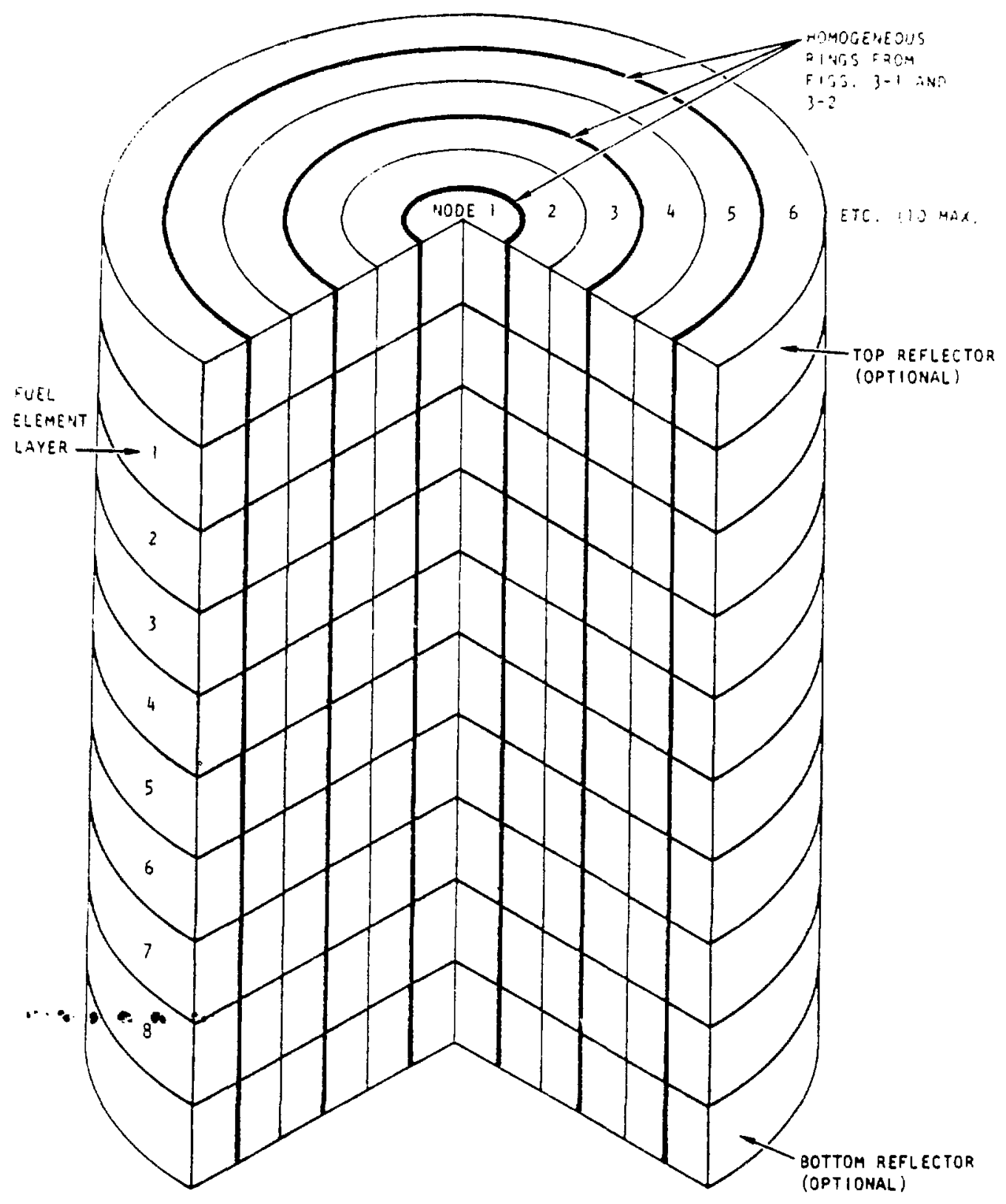

Figure 2.4. Typical sors model.? 


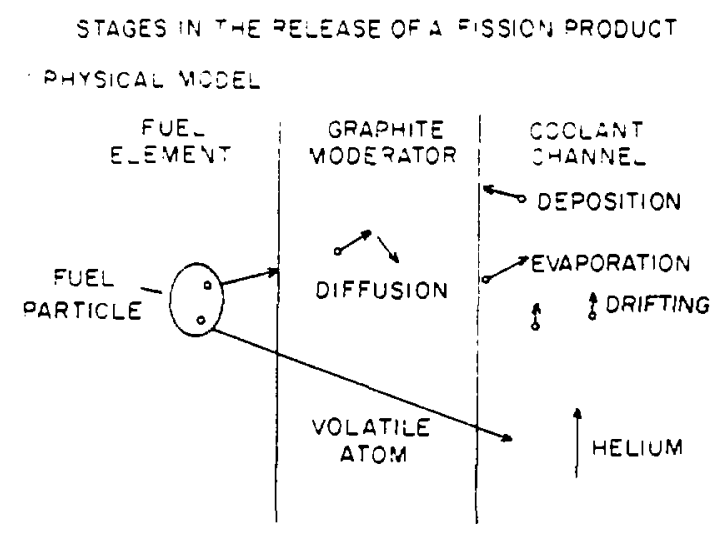

2 MATHEMATICAL MODEL

VOLATILE ATOMS

FUEL

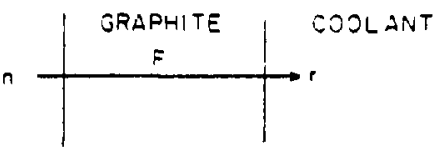

NON VOLATILE ATOMS

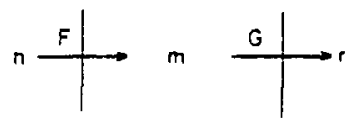

Figure 2.5. Barriers to the release of fission products.

GENERALIZED DECAY CHAIN

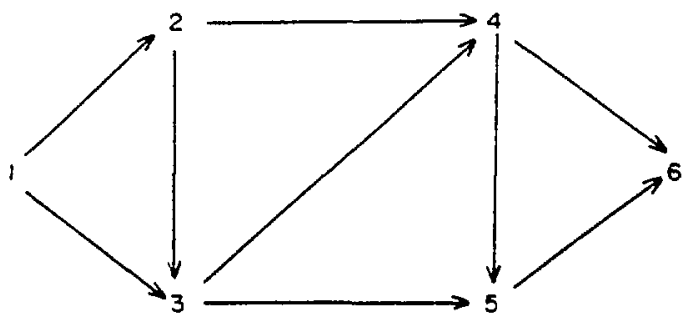

Figure 3.1. Generalized decay chain structure. 


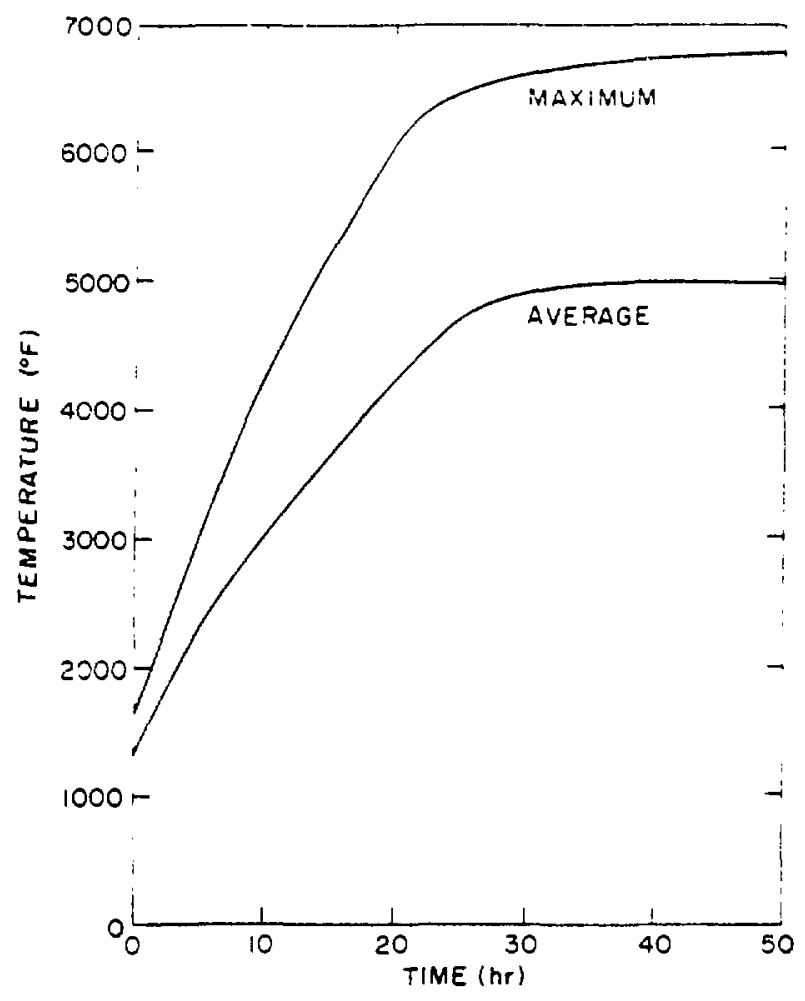

Figure 3.2. Evclution of the average and maximum temperature of the core.

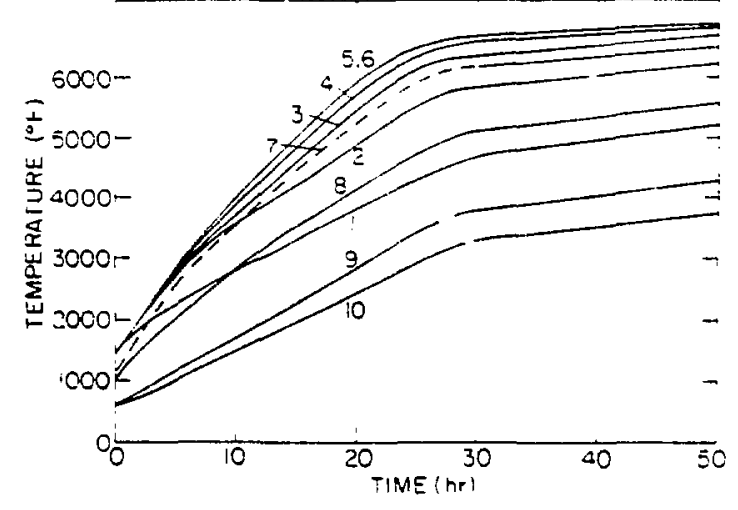

Figure 3.3. Evolution of the temperature of the 10 segments in the central part of the core. 
PROCEDURE USED TO CALCULATE THE RELEASE FROM THE FLEL

Step: : FRCALC

Equations

Separate equations for the amount of an element in each segment of the core, 4.14 .

Release rate in each segment calculated from empirical fuel model.

Decay neglected.

Solution

Crude, using a large time step, stepwise integration.

Result

Amount of each eleme:t in each segment of the core versus time.

Table of iractional release rates averaged over the core.

Step ::2 Main Program

Equations

Equation for the total amount of an isotope in the fuel in the whole reactor, 4.4.

Release rate is the approximate value calculated in FKCALC.

Each decay chain treated separately.

Solution

Accurate, small time step, Hammings method.

Result

Total amount of an isotope within the fuel particles and total amount outside the fuel particles versus tire.

Figure 4.1. Sumbary of mathematical approach to release from the fuel. 


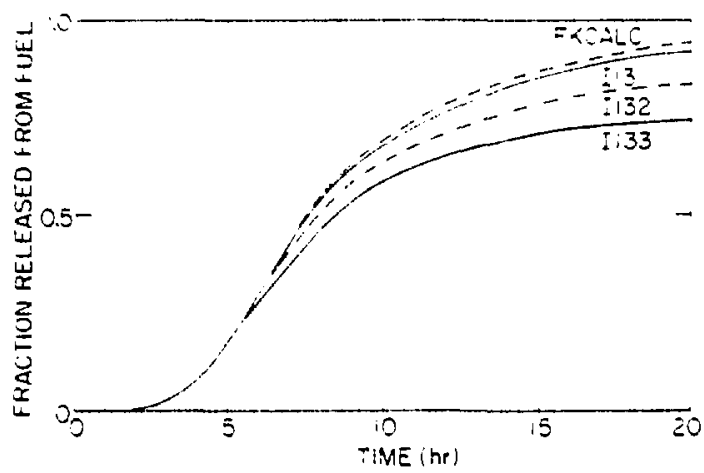

Figure 4.2, Comparison of the release from the fuel of $131 \mathrm{I}, 132 \mathrm{I}, 133 \mathrm{I}$ predicted by FKCALC and SORS.

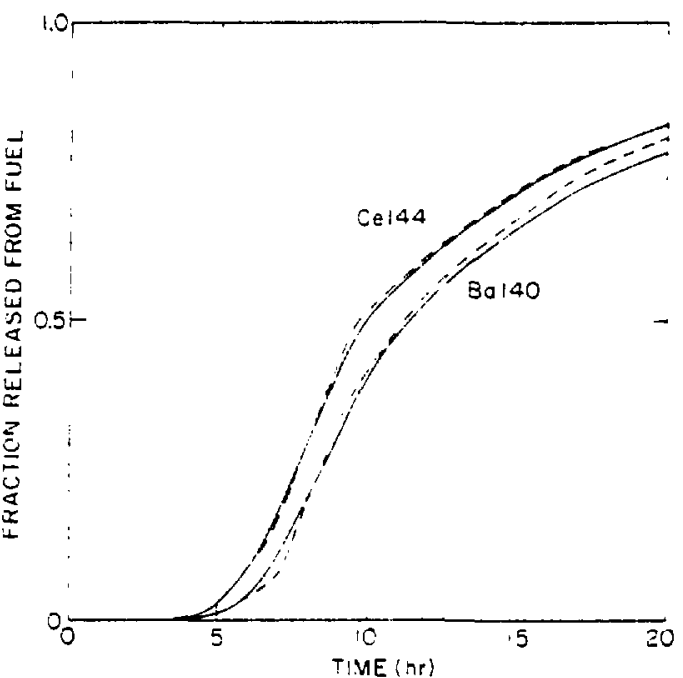

Figure 4.3. Comparison of the release from the fuel of $144 \mathrm{Ce}, 140 \mathrm{Ba}$ predicted by FKCALC and SORS. 


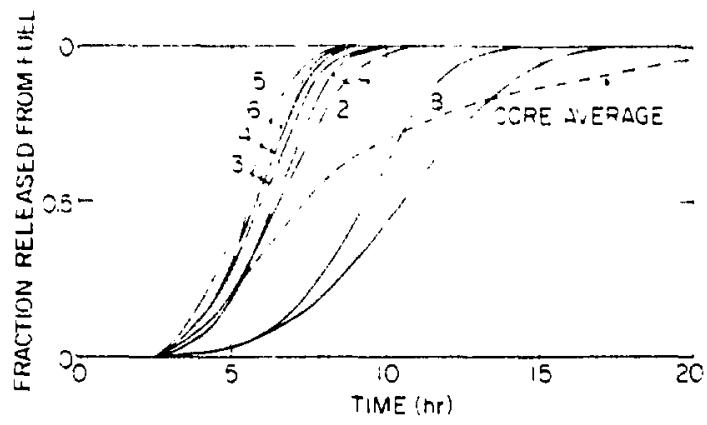

Figure 4.4. Fraction released from fuel for each segment in the central part of the core, predicted by FKCALC.

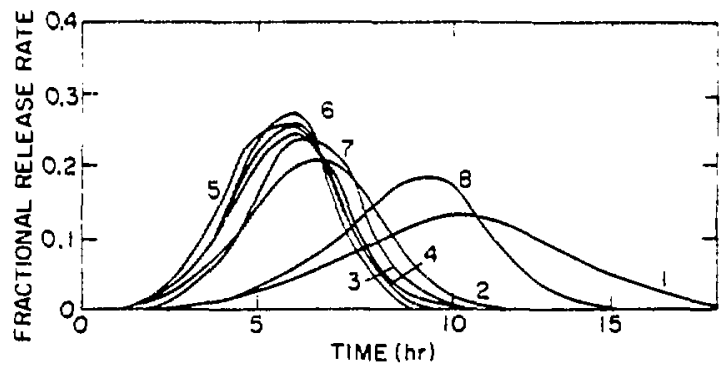

Figure 4.5. Fractional release rate from fuel for each segment in the central part of the core, predicted by FKCALC.

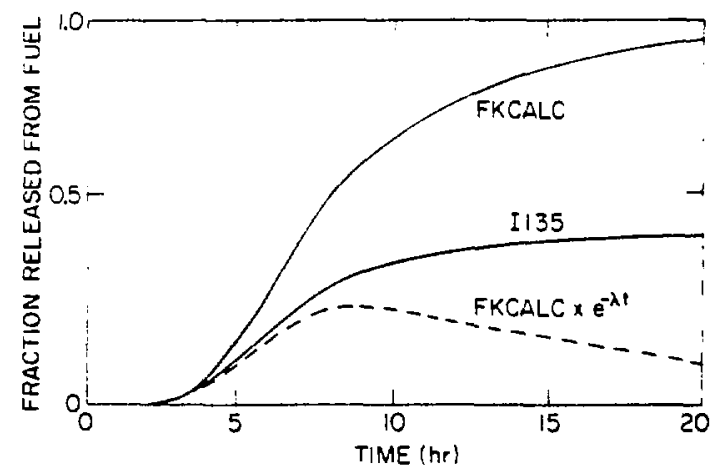

Figure 4.6. Release from the fuel for $135 \mathrm{I}$, predicted by FRCALC and SORS. 


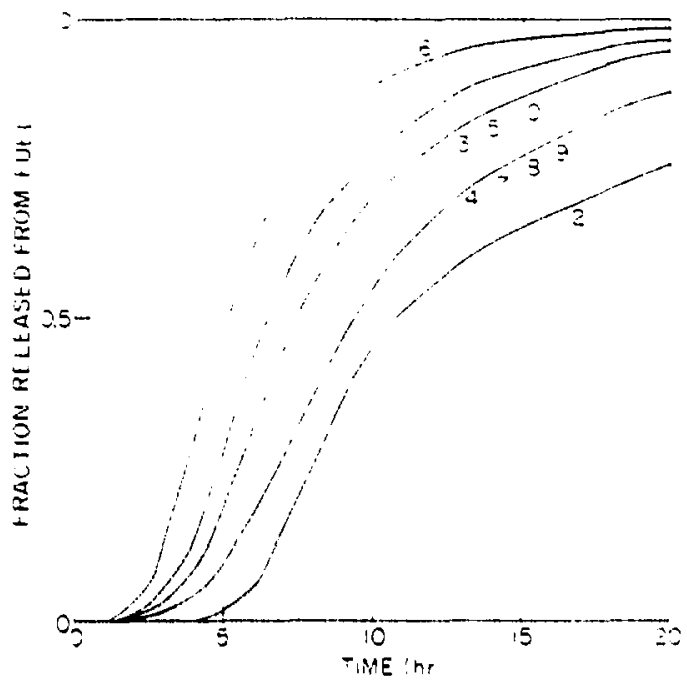

Figure 5.1. The release from the fuel predicted by FKCALC using Fuel Yodel I.

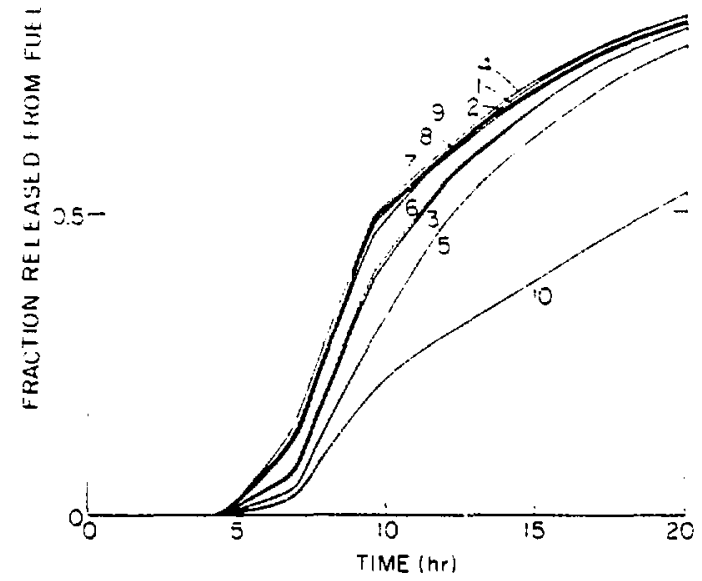

Figure 5.2. The release from the fuel predicted by FKCALC using Fuel Model II. 


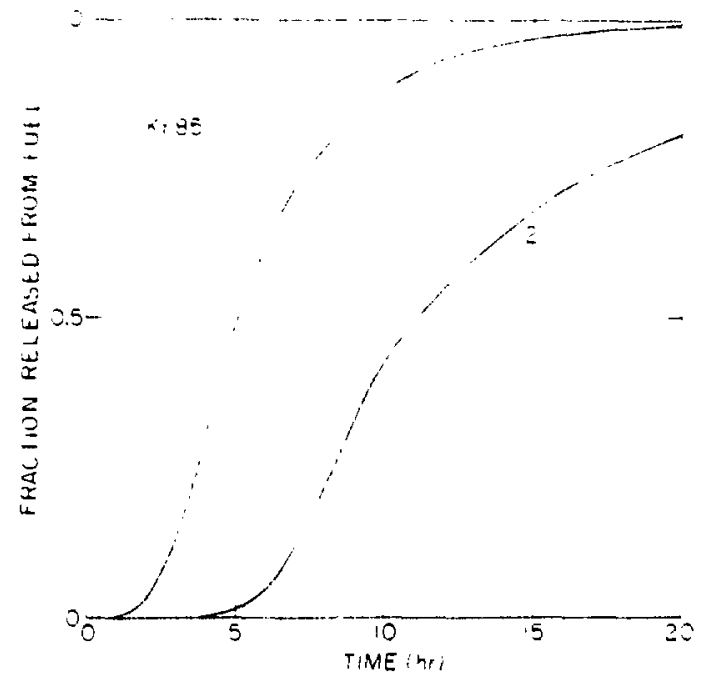

Figure 5.3. Comparison of the two fuel models for ${ }^{85} \mathrm{Kr}$.

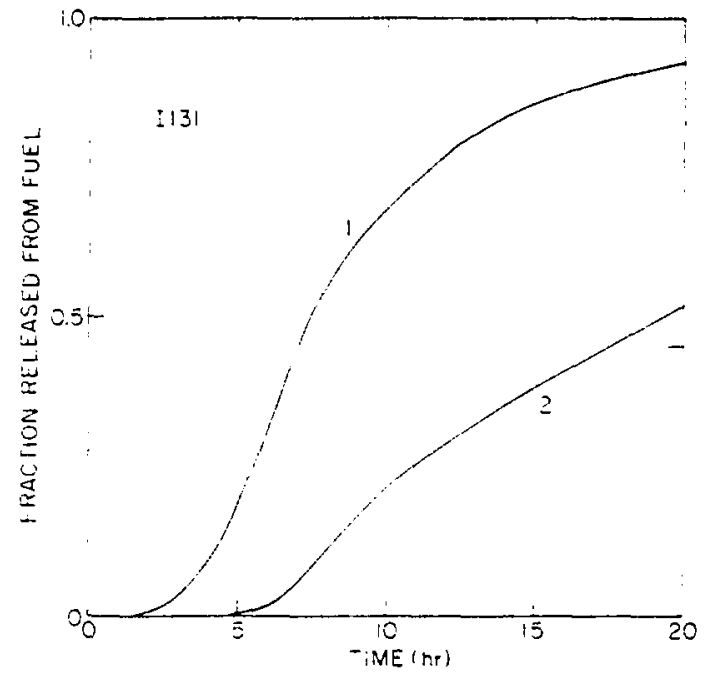

Figure 5.4. Comparison of the two fuel models for ${ }^{131}$ I. 


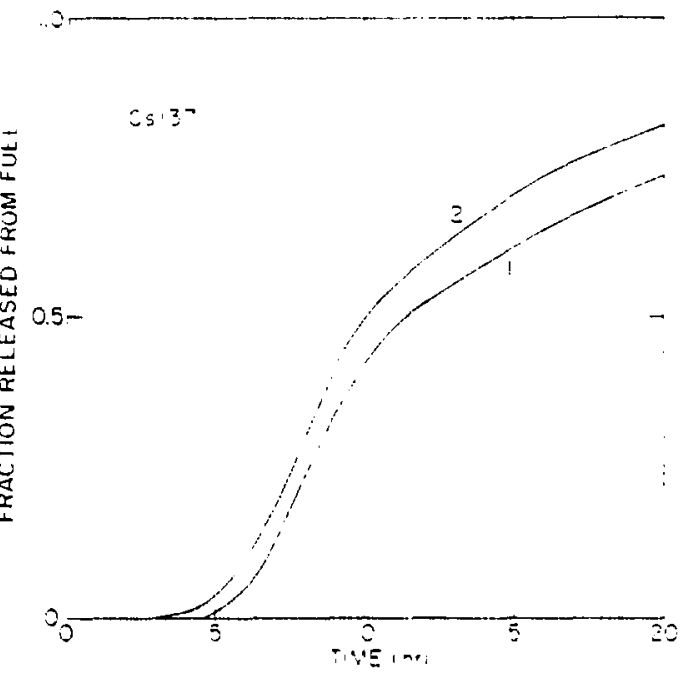

Figure 5.5. Comparison of the two Evel models for $13 i \mathrm{Cs}$.

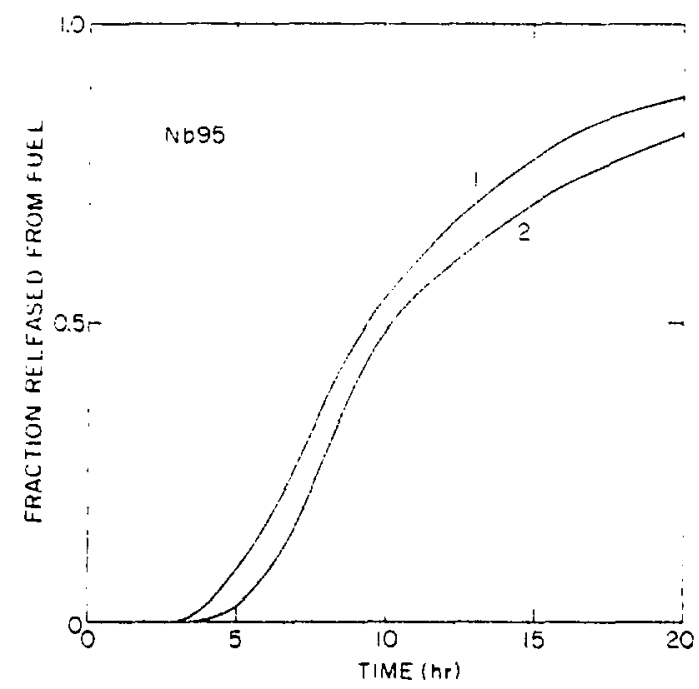

Figure 5.6. Comparison of the two fuel models for ${ }^{95} \mathrm{Nb}$. 


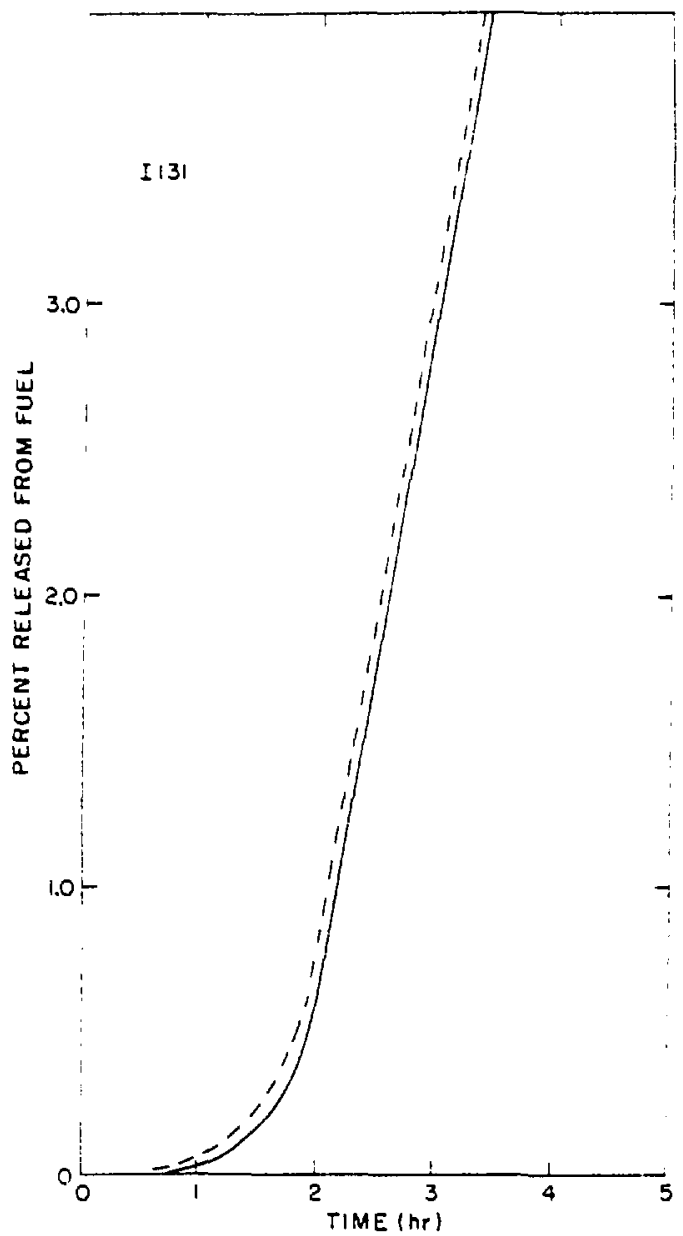

Figure 5.7. The effect of the model for fuel failure using Fuel Model I, ${ }^{13} 1$. 


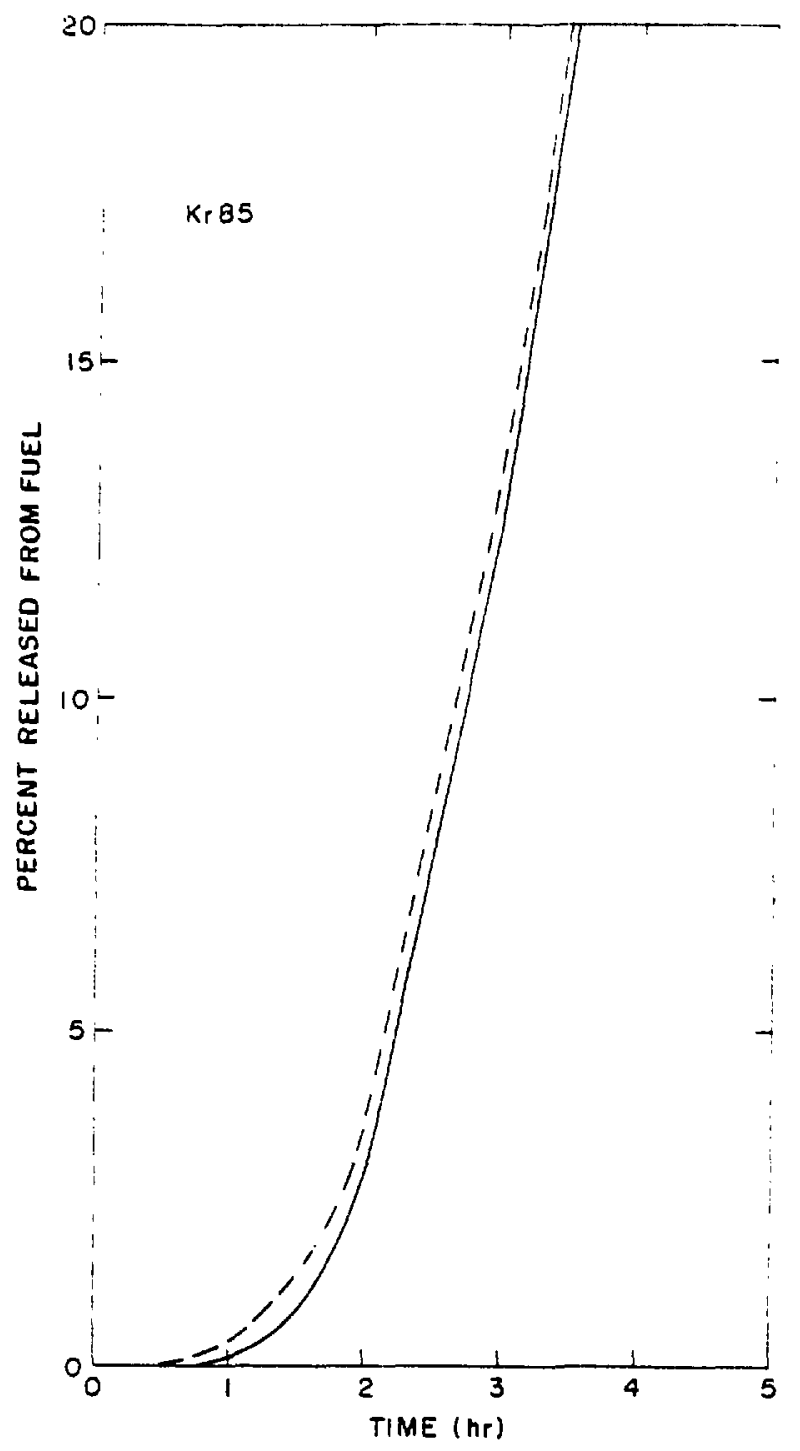

Figure 5.8. The effect of the model for fuel failure using Fuel Model $\mathrm{I}, 85 \mathrm{kr}$. 


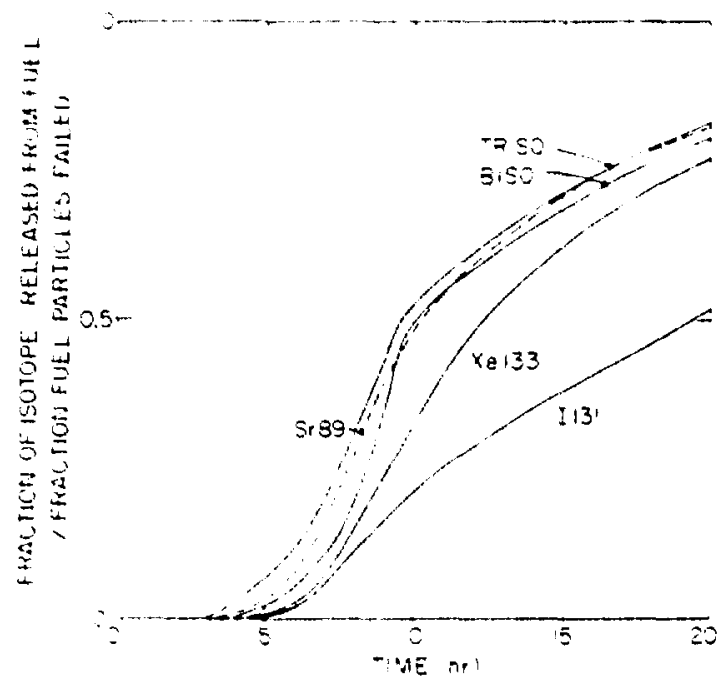

Figure 5.9. The eitect of the model for fuel fallure using Fuel Model II.

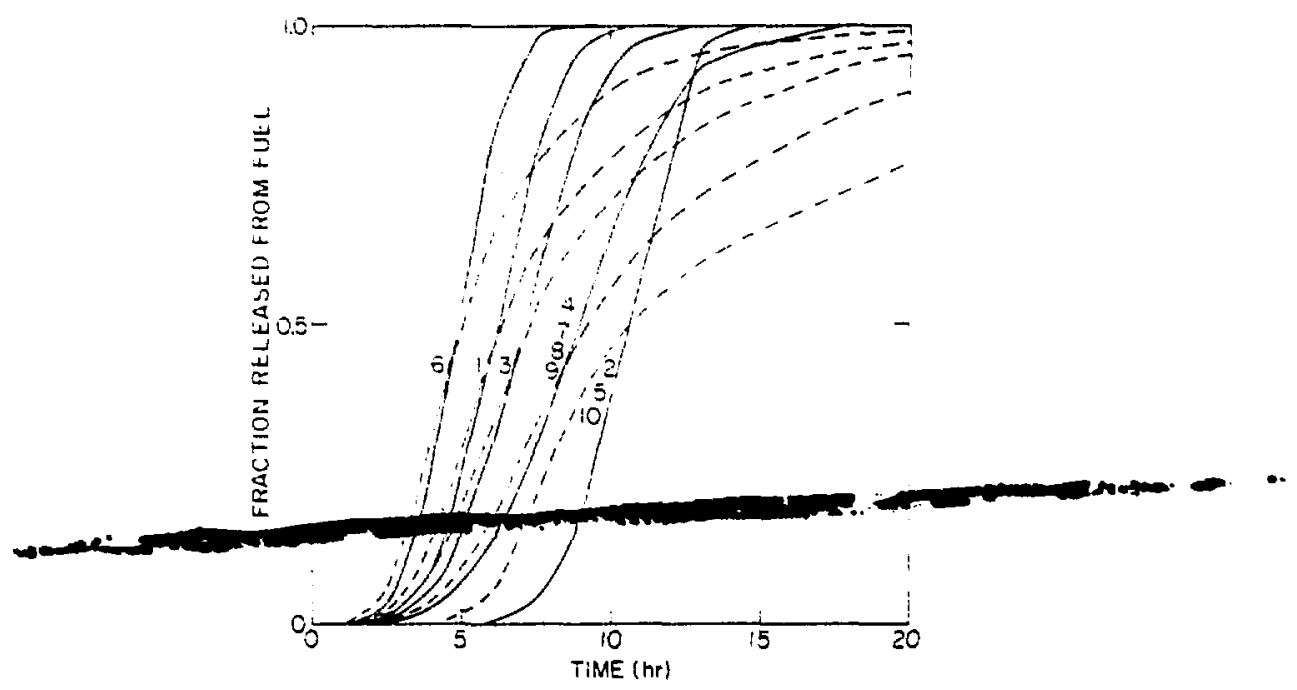

Figure 5.10. Comparison of the release from the fuel for a uniform core with the release for a core divided into 56 segments. 
CONCENTRATION PROFILES IN GRAPHITE ASSUMED IN SORSG
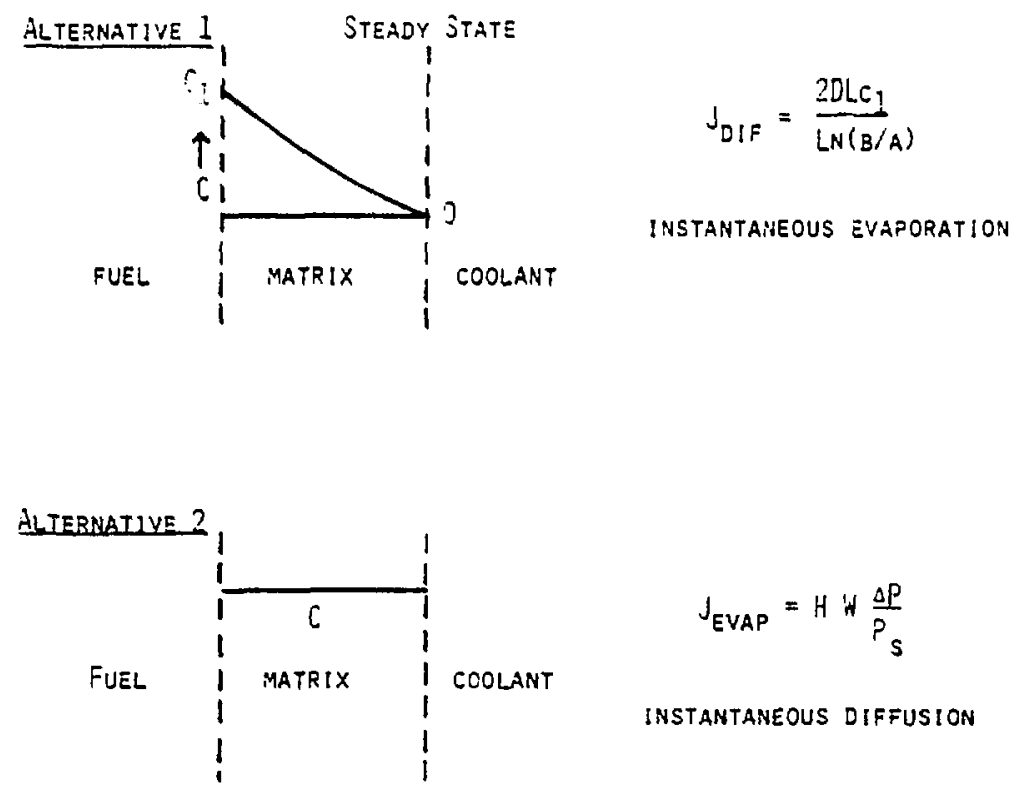

NeT RELEASE = LESSER OF $\begin{aligned} & J_{\text {DIFF }} \\ & J_{\text {EVAP }}\end{aligned}$

Figure 6.1. The two alternative approximations for diffusion used in SORSG. 


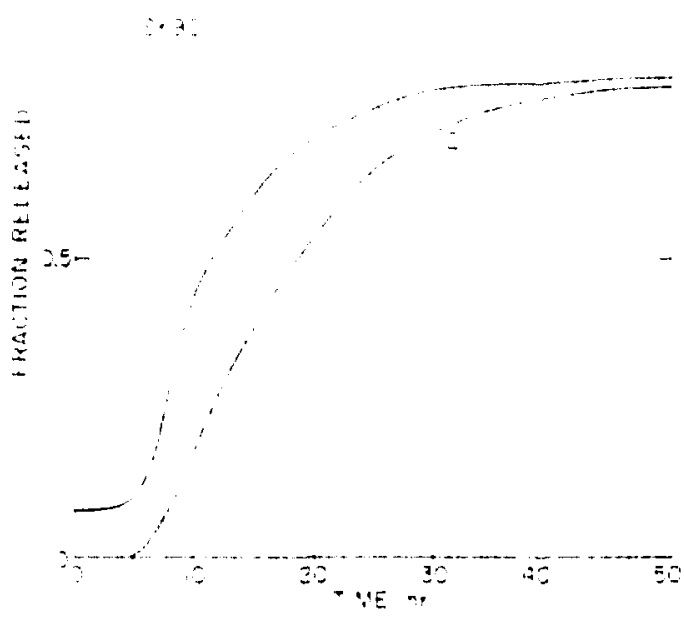

Figure 6.2. The amount of ${ }^{n}$ Sr released trom the fuel, curve 1, and the amount that has difiused through the sraphite, curve 2, on the assumption that evaporation is instantanenus and no redeposition occurs.

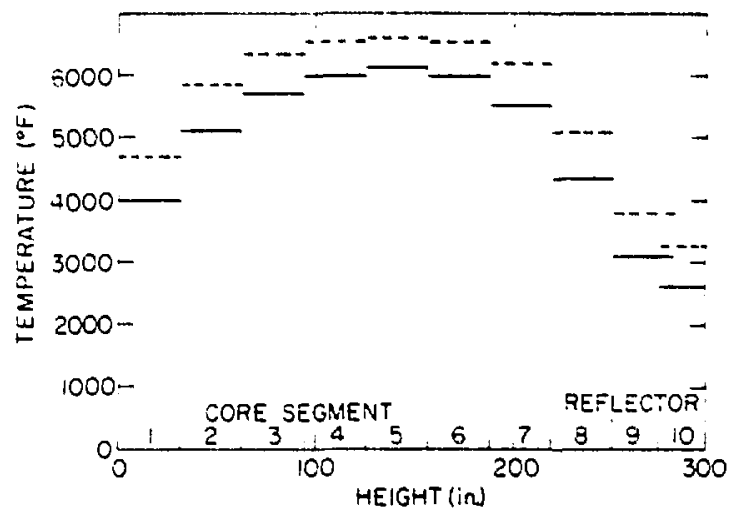

Figure 7.1. Variation of temperature along the coolant channels in the central portion of the core. The full curve refers to 21 hours and the dashed curve to 29 hours. 


\section{T.K. SHERWOOD AND R.L. PIGFORD}

\section{ABSORPTION AND EXTRACTION P. 82}

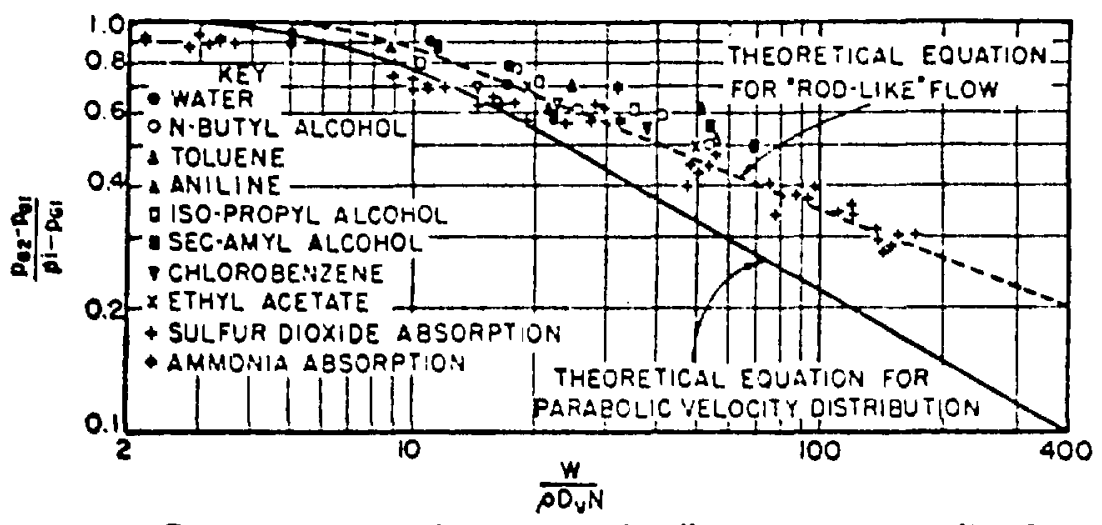

Data on mass transfer in 3 wetted-wall torer with streamline tox:.

$X$ AXIS is $\frac{\pi}{4}$ (1/'stagnation NUMber') $\equiv$ GRaetz Number

$y$ axis is $\frac{P_{2}-P_{1}}{V P-P_{1}}$

Figure 7.2. Experimental data and theoretical curves for mass transfer in a fluid flowing through a cylindrical channel. 


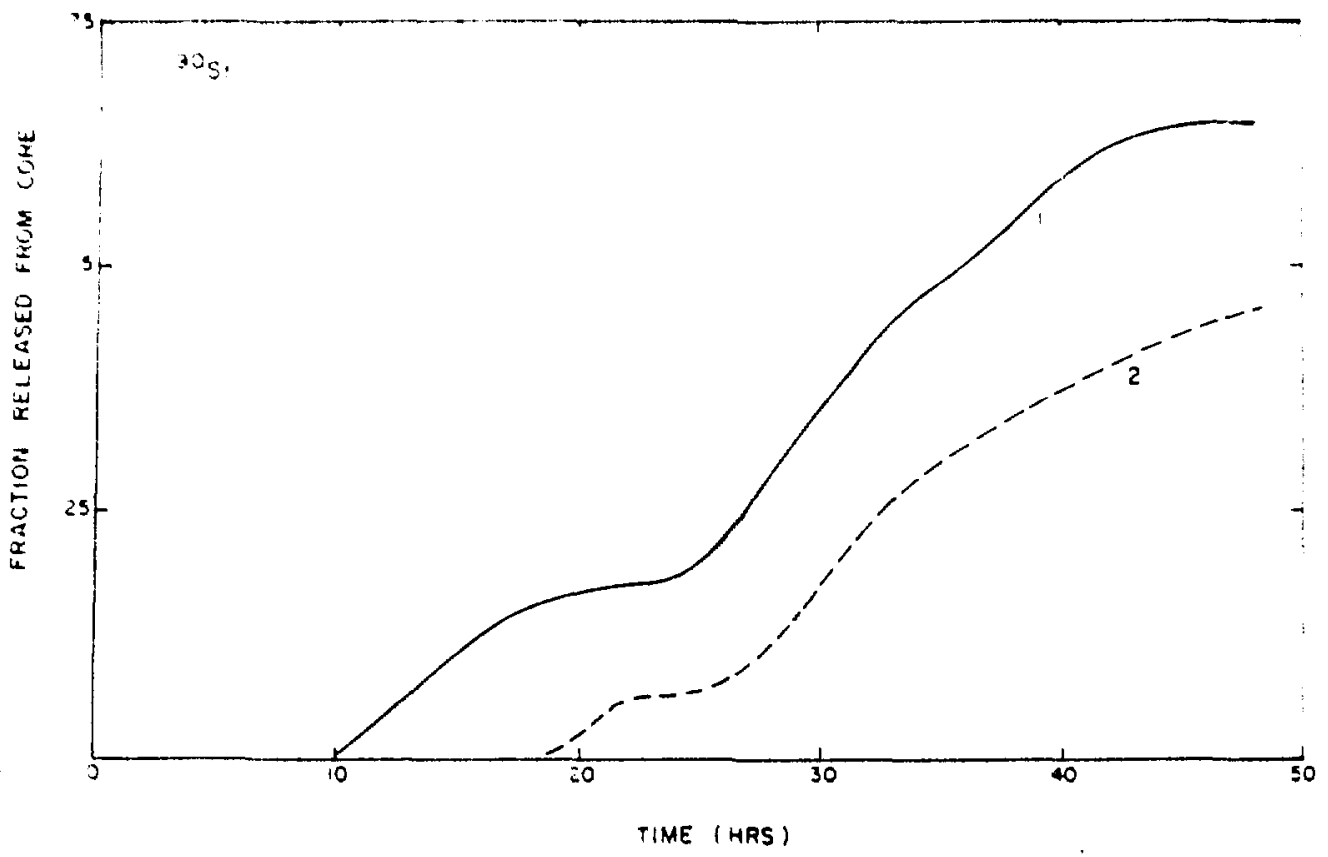

Flgure 7.3. Comparison of the output of SORSt and the results predicted by the code if the expression for the evaporation rate is change to Eq. $(7,27)$.

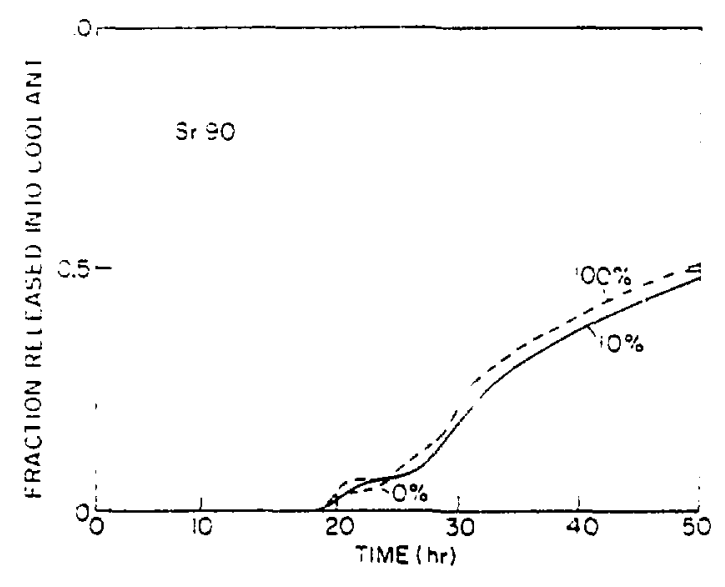

Figure 7.4. Comparison of the release of ${ }^{90} \mathrm{Sr}$ assuming that initially $0 \%, 10 \%$ or $100 \%$ of the 90 Sr has been released from the fuel particles. 


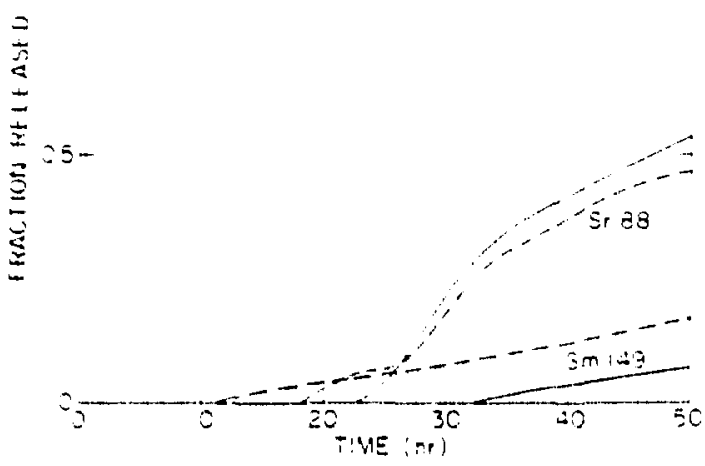

Figure i.j. Comparison of the results using SORSG and EVAP. The full curve is predicted by EVAP and the dashed curve is predicted by SORSG. 